OPEN ACCESS

Edited by: Joao P. B. Viola, Instituto Nacional de Cancer (INCA),

Brazil

Reviewed by:

Miriam B. F. Werneck, Universidade Federal do Rio de

Janeiro, Brazil Jorge Galindo-Villegas,

University of Murcia, Spain

*Correspondence:

Li-xin Xiang

xianglx@zju.edu.cn; Jian-zhong Shao

shaojz@zju.edu.cn

Specialty section:

This article was submitted to Molecular Innate Immunity, a section of the journal

Frontiers in Immunology

Received: 10 October 2016 Accepted: 21 December 2016

Published: 09 January 2017

Citation:

Wan F, Hu C-b, Ma J-x, Gao K, Xiang L-x and Shao J-z (2017) Characterization of $\gamma \delta T$ Cells from Zebrafish Provides Insights into Their Important Role in Adaptive Humoral Immunity.

Front. Immunol. 7:675. doi: 10.3389/fimmu.2016.00675

\section{Characterization of $\gamma \delta$ T Cells from Zebrafish Provides Insights into Their Important Role in Adaptive Humoral Immunity}

\author{
Feng Wan ${ }^{1,2}$, Chong-bin $\mathrm{Hu}^{1,2}$, Jun-xia Ma ${ }^{1,2}, \mathrm{Ke} \mathrm{Gao}^{1,2}$, Li-xin Xiang ${ }^{1,2 *}$ and \\ Jian-zhong Shao ${ }^{1,2,3 *}$ \\ ${ }^{1}$ College of Life Sciences, Zhejiang University, Hangzhou, China, ${ }^{2}$ Key Laboratory for Cell and Gene Engineering of Zhejiang \\ Province, Hangzhou, China, ${ }^{3}$ Laboratory for Marine Biology and Biotechnology, Qingdao National Laboratory for Marine \\ Science and Technology, Qingdao, China
}

$\gamma \delta T$ cells represent an evolutionarily primitive T cell subset characterized by distinct $T$ cell receptors (TCRs) and innate and adaptive immune functions. However, the presence of this $T$ cell subset in ancient vertebrates remains unclear. In this study, $\gamma \delta T$ cells from a zebrafish (Danio rerio) model were subjected to molecular and cellular characterizations. The constant regions of zebrafish TCR- $\gamma$ (DrTRGC) and $\delta$ (DrTRDC) were initially identified. Zebrafish $\gamma \delta$ T cells accounted for $7.7-20.5 \%$ of the total lymphocytes in spleen, head kidney, peripheral blood, skin, gill, and intestine tissues. They possess typical morphological features of lymphocytes with a surface phenotype of $\gamma^{+} \delta^{+} \mathrm{CD} 4^{-} \mathrm{CD} 8^{+}$. Zebrafish $\gamma \delta$ T cells functionally showed a potent phagocytic ability to both soluble and particulate antigens. They can also act as an antigen-presenting cell to initiate antigen $(\mathrm{KLH})$-specific CD4 ${ }^{+} \mathrm{T}_{\mathrm{KLH}}$ cell activation and to induce B cell proliferation and IgM production. Particularly, zebrafish $\gamma \delta T$ cells also play a critical role in antigen-specific lgZ production in intestinal mucus. These findings demonstrated that $\gamma \delta T$ cells had been originated as early as teleost fish, which providing valuable insights into the evolutionary history of $T$ cell subset. It is anticipated that this study would be used as a guide to develop a zebrafish model for the cross-species investigation of $\gamma \delta$ T cell biology.

Keywords: zebrafish $\gamma \delta \mathrm{T}$ cells, identification, origin of T cell subset, antigen-presenting cells, adaptive humoral immunity, mucosal IgZ antibody

\footnotetext{
Abbreviations: DrTRGC, Danio rerio T cell receptor gamma constant region; DrTRDC, Danio rerio $\mathrm{T}$ cell receptor delta constant region; DrTRAC, Danio rerio T cell receptor alpha constant region; DrTRBC, Danio rerio $\mathrm{T}$ cell receptor beta constant region; KLH, keyhole limpet hemocyanin; MHC-II, MHC class II; CD4 ${ }^{+} \mathrm{T}_{\mathrm{KLH}}$, KLH-stimulated CD4 ${ }^{+} \mathrm{T}$ cell; BLAST, basic local alignment search tool; FITC-KLH, FITC-conjugated KLH; FITC-A.h, FITC-labeled Aeromonas hydrophila; FCM, flow cytometry; CsA, cyclosporin A; DrCD4, Danio rerio CD4; DrCD80/86, Danio rerio CD80/86; DrCD83, Danio rerio CD83; DrMHC-II, Danio rerio MHC class II; DrIgM, Danio rerio IgM; DrCD40, Danio rerio CD40; DrCD154, Danio rerio CD154; DrIgZ, Danio rerio IgZ.
} 


\section{INTRODUCTION}

$\mathrm{T}$ cells are fundamental players of adaptive immune responses in vertebrates. The $\mathrm{T}$ cell receptor (TCR) is expressed as a heterodimeric protein on the cell surface of all $\mathrm{T}$ cells and confers the exquisite specificity to foreign antigens that typifies the adaptive immune system. T cells can be divided into two subsets on the basis of expressed TCR genes: $\alpha \beta$ T cells and $\gamma \delta$ T cells. $\gamma \delta$ T cells are a distinct subset of $\mathrm{CD}^{+} \mathrm{T}$ cells containing TCRs encoded by $\mathrm{V} \gamma$ and $\mathrm{V} \delta$ gene segments, which were first shown to exist in humans after the genes encoding their TCRs were cloned in the mid-1980s $(1,2)$. The discovery of $\gamma \delta \mathrm{T}$ cells is based on the structural similarities between their TCRs and those of $\alpha \beta$ T cells. In contrast to conventional $\alpha \beta \mathrm{T}$ cells, $\gamma \delta \mathrm{T}$ cell repertoire is rather restricted because canonical $\gamma \delta$ TCRs are expressed in specific anatomical locations (3). $\gamma \delta \mathrm{T}$ cells possess unique features; for instance, they do not display MHC restriction, and they do not recognize peptides processed from complex protein antigens by antigen-presenting cells (APCs); instead, $\gamma \delta \mathrm{T}$ cells distinguish unconventional antigens, such as phosphorylated microbial metabolites and lipid antigens (4). Moreover, it is not needed the presentation of those antigens by MHC-I and MHC-II, which is in agreement with the absence of CD4 or CD8 expression in the majority of $\gamma \delta \mathrm{T}$ cells (5). In human peripheral blood, $\gamma \delta \mathrm{T}$ cells constitute $2-10 \%$ of the total T cell pools. High proportions of $\gamma \delta$ $\mathrm{T}$ cells are also found in the intestines, lungs, reproductive tract, and skin; as such, these cells may play a crucial role in mucosal immunity (6). $\gamma \delta \mathrm{T}$ cells contain TCRs that also function as pattern recognition receptors; for these reasons, these cells have been considered an evolutionarily primitive lymphocyte population functionally characterized "in between" innate and adaptive immune systems (7). Therefore, $\gamma \delta \mathrm{T}$ cells possibly link innate immunity to adaptive immunity, and thus they have become much attractive for the study of regulatory mechanisms across innate and adaptive immunity. On the other hand, $\gamma \delta$ T cells may also be used as a model system to elucidate lymphocyte evolution, which is a key event in adaptive immunity originating from ancient vertebrates to humans (8). To date, $\gamma \delta \mathrm{T}$ cells have been extensively identified in humans and other mammals, including mice, sheep, cattle, and pigs; nevertheless, their existence or occurrence in ancient vertebrates remains poorly understood (9). Therefore, $\gamma \delta$ T cells should be identified in evolutionarily lower vertebrates.

In evolutionary terms, teleost fish possess a complex innate immunity; they also comprise an ancient recognizable adaptive immune system containing $\mathrm{T}$ and $\mathrm{B}$ lymphocytes with somatically rearranged antigen receptors, $\mathrm{MHC}$ molecules, oldest immunoglobulins (Igs) in systematic (IgM) and mucosal (IgZ/T) immune systems, and immunological memory (10). Thus, teleost fish have been used as an efficient model organism to determine fundamental immunological events, such as the cooperation between innate immunity and adaptive immunity during the early evolution of adaptive immune systems and the origin of lymphocytes with typical adaptive natures from innate immune cells. Using this model, we may gain insights into the functional development of adaptive immune systems throughout vertebrate evolution. As a primitive lymphocyte subset that possibly originated in early evolutionary stages, $\gamma \delta \mathrm{T}$ cells may play prominent functions in teleost fish. Hence, $\gamma \delta \mathrm{T}$ cells in fish should be investigated to obtain key information regarding the ontogeny of innate and adaptive immunity systems in vertebrates.

In our study, $\gamma \delta$ T cells from a zebrafish (Danio rerio) model were subjected to molecular and cellular identification and functional characterization. We found that zebrafish $\gamma \delta \mathrm{T}$ cells share typical morphological features of lymphocytes with a surface phenotype of $\gamma^{+} \delta^{+} \mathrm{CD} 4^{-} \mathrm{CD} 8^{+}$and potently phagocytose soluble and particulate antigens. In vitro antigen presentation and in vivo antibody blockade assays revealed that zebrafish $\gamma \delta \mathrm{T}$ cells can initiate $\mathrm{Ag}$-specific $\mathrm{CD}^{+} \mathrm{T}$ cell proliferation and subsequently induce $B$ cell activation and IgM production. This finding suggested that $\gamma \delta \mathrm{T}$ cells participate in the full activation of the systematic adaptive humoral immunity in zebrafish. Zebrafish $\gamma \delta \mathrm{T}$ cells also play a critical role in antigen-specific mucosal IgZ production in the intestinal mucus. These observations showed the innate-like nature of teleost $\gamma \delta$ T cells in the interface of innate and adaptive immunities. These cells also comprise a major population of APCs functioning in systematic and mucosal adaptive immunities. To our knowledge, this study is the first to demonstrate the existence of $\gamma \delta \mathrm{T}$ cells that functionally link innate and adaptive immunities in a fish species. This study not only provided further insights into fish immunology but also helped enhance our cross-species understanding of the evolutionary history of the $\gamma \delta \mathrm{T}$ family and its cellular regulatory networks. Therefore, zebrafish may be used as a new model organism to investigate $\gamma \delta$ T cell biology and $\gamma \delta$ $\mathrm{T}$ cell-mediated diseases because of the molecular and functional conservation of $\gamma \delta$ T cells between teleost fish and mammals and the crucial roles of $\gamma \delta \mathrm{T}$ cells in immune regulation, infectious diseases, and autoimmune disorders.

\section{MATERIALS AND METHODS}

\section{Experimental Fish}

Wild-type $\mathrm{AB}$ zebrafish were bred and maintained in a circulating water bath at $28^{\circ} \mathrm{C}$ under standard conditions (11). All fish used in the experiments were offspring of a single $A B$ strain parent pair after five generations of partial inbreeding (12). Healthy fish, as determined by their general appearance and activity level, was used in our study. All animal work in this paper was conducted according to relevant national and international guidelines. All animal care and experimental procedures were approved by the Committee on Animal Care and Use and the Committee on the Ethic of Animal Experiments of Zhejiang University.

\section{Molecular Cloning}

The constant regions of the cDNAs of zebrafish TCR- $\alpha$, TCR$\beta$, TCR- $\gamma$, and TCR- $\delta$ (DrTRAC, DrTRBC, DrTRGC, and DrTRDC, respectively) were cloned from spleen and intestine tissues. Total RNAs were extracted using RNAiso Plus (TaKaRa). cDNA sequences were obtained through RT-PCR by using primers designed in accordance with the predicted sequences in NCBI (AF425590.1, AY973884.1, and CAK05280.1; Table S1 in Supplementary Material) (13-16). Gene organizations (intron/ exon boundaries) were elucidated by comparing the cDNAs with 
genome sequences, and figures were drawn using GeneMaper 2.5. Protein sequence alignment was generated using Clustal X (1.81), and phylogenetic analyses were conducted in MEGA version 6.0.

\section{Preparation of Recombinant Proteins}

For recombinant protein preparation, cDNAs encoding the extracellular region of DrTRAC, DrTRBC, DrTRGC, and DrTRDC were amplified through RT-PCR by using primers containing an EcoRI site added to the $5^{\prime}$ end and a XhoI site added to the $3^{\prime}$ end. The PCR products were digested and ligated into pET28a (Invitrogen Life Technologies). Then, plasmid DNAs were transformed into Escherichia coli Rosetta (Novagen). Single colony was inoculated into $100 \mathrm{~mL}$ of Luria-Bertani medium containing kanamycin $(50 \mu \mathrm{g} / \mathrm{mL})$ and shaken at $37^{\circ} \mathrm{C}$ until $\mathrm{OD}_{600}$ reached 0.6. Afterward, isopropyl- $\beta$-D-thiogalactoside was added to a final concentration of $1 \mathrm{mM}$. The culture was shaken continually at $37^{\circ} \mathrm{C}$ for $6 \mathrm{~h}$. Protein expression levels were assessed through $10 \%$ SDS-PAGE followed by Coomassie brilliant blue R250 staining.

\section{Prediction of Abs}

Abs against DrTRGC, DrTRDC, DrTRAC, DrTRBC, and CD $8 \alpha$ were produced by an approach based on the prediction of antigen epitopes on the surfaces of these molecules (17). Briefly, ABCPred, BepiPred, MAPPP, and IEDB online software were used to search the epitope sequences (Table S2 in Supplementary Material), and their hydrophilic and antigen indices were evaluated by using DNAStar (18). Their 3D structures were predicted by utilizing SWISS-MODEL to detect whether the predicted antigen epitopes were exposed on the surfaces of the corresponding proteins. The specificity of the predicted sequences was confirmed by BLAST. The amino acid sequences of the antigen epitopes were chemically synthesized, purified through HPLC, and coupled to OVA at a ratio of 10:10 $\mathrm{mg}$ (carrier/peptide). New Zealand white rabbits $(\sim 1.5 \mathrm{~kg})$ and Balb/c mice $(\sim 30 \mathrm{~g})$ were immunized with OVA-coupled peptides ( $1 \mathrm{mg}$ for rabbits and $0.1 \mathrm{mg}$ for mice, respectively) in CFA on days 1 and 3 and in IFA on days 28 and 35. A week after the final immunization was administered, the animals were bled when Ab titers were above 1:10,000, as determined by ELISA with recombinant proteins adsorbed onto a solid phase. Abs were affinity purified by protein-G agarose as previously described (19). The specificity of Abs was detected through Western blot analyses, in which the blocking peptides $(5 \mu \mathrm{g} / \mathrm{mL})$ were also included $(19,20)$. Other Abs, including anti-DrCD4, anti-DrCD80/86, anti-DrCD83, anti-DrCD154, anti-DrCD40, anti-DrIgM, anti-DrMHC-II, and anti-DrIgZ used in this study, were prepared in our laboratory (21-24).

\section{Magnetic Sorting (MACS)}

For the MACS of $\gamma \delta$ T cells, blood, spleen, and head kidney tissues were collected in ice-cold $\mathrm{Ca}^{2+} / \mathrm{Mg}^{2+}$-free HBSS with heparin $(10 \mathrm{U} / \mathrm{mL})$. Single-cell suspensions of the spleen and head kidney were prepared by gently teasing the tissues through an $80-\mu \mathrm{m}$ nylon mesh filter. Leukocytes were enriched from the cell suspensions through Ficoll-Hypaque $(1.080 \mathrm{~g} / \mathrm{mL})$ centrifugation at 2,500 $\mathrm{rpm}$ for $25 \mathrm{~min}$ at room temperature and washed with ice-cold $\mathrm{Ca}^{2+} / \mathrm{Mg}^{2+}$-free HBSS. The $\gamma \delta \mathrm{T}$ cells were subjected to MACS, as described in a previous study (21). In brief, the cell suspension was blocked with $5 \%$ normal goat serum for $15 \mathrm{~min}$ at $10^{\circ} \mathrm{C}$, incubated with anti- $\gamma$ or anti- $\delta$ for $15 \mathrm{~min}$ at $10^{\circ} \mathrm{C}$, washed with MACS buffer (PBS containing $2 \mathrm{mM}$ EDTA and $0.5 \%$ $\mathrm{BSA}$ ), and incubated for $15 \mathrm{~min}$ at $10^{\circ} \mathrm{C}$ with anti-IgG magnetic beads (Miltenyi Biotec). The cell suspension was applied to an LS separation column in accordance with the manufacturer's instructions. Positive cells were cultured in L-15 medium (Life Technologies) supplemented with 10\% FBS (Life Technologies), $100 \mathrm{U} / \mathrm{mL}$ penicillin, and $100 \mu \mathrm{g} / \mathrm{mL}$ streptomycin at $28^{\circ} \mathrm{C}$ overnight to detach the magnetic beads. The purity of the sorted $\gamma \delta \mathrm{T}$ cells was detected through RT-PCR and flow cytometry (FCM). In addition, $\alpha \beta$ T cells for control purpose were sorted by similar protocol with the exception of incubating cells with anti- $\alpha$ or anti- $\beta$ Abs instead of anti- $\gamma$ or anti- $\delta$ Abs.

\section{FCM Analysis}

The cells for FCM analysis were blocked with 5\% normal goat serum for $1 \mathrm{~h}$ at $4^{\circ} \mathrm{C}$ and then incubated with the corresponding primary Abs, and non-specific mouse or rabbit IgG served as an isotype control. Afterward, the cells were washed and further incubated with secondary Abs, namely, PE-conjugated goat antimouse IgG and FITC-conjugated goat anti-rabbit IgG, for $1 \mathrm{~h}$ at $4^{\circ} \mathrm{C}$. Fluorescence signals were determined by using a FACScan flow cytometer (BD Bio-sciences) at $488 \mathrm{~nm}$. FCM analysis was based on forward/side scatter (FSC/SSC) characteristics and PE/FITC-conjugated fluorescence with CellQuest program as previously described $(11,25)$. At least 10,000 events were collected from the lymphocyte gate.

\section{Immunofluorescence Staining}

For sorted cell staining, the cells were fixed with $2 \%$ paraformaldehyde for $10 \mathrm{~min}$ at room temperature, blocked with $5 \%$ normal goat serum and incubated with primary Abs (rabbit anti- $\gamma$, anti- $\beta$, anti-DrCD4, anti-DrCD8; mouse anti- $\delta$, anti- $\alpha$ ) at $4^{\circ} \mathrm{C}$ for $1 \mathrm{~h}$. In parallel, the non-related Abs (rabbit IgG and mouse IgG) were used as negative controls. For intestine staining, cryosections were prepared and fixed for $5 \mathrm{~min}$ in 95\% ethyl alcohol before incubating with primary Abs. Background autofluorescence was eliminated by treatment of cryosections for $10 \mathrm{~min}$ with $0.1 \mathrm{M}$ glycine ( $\mathrm{pH}$ 2.3). After washing, cells or intestine tissues were incubated with secondary Abs (PE-conjugated goat anti-mouse IgG and FITC-conjugated goat anti-rabbit IgG) at $4^{\circ} \mathrm{C}$ for $1 \mathrm{~h}$. Additional staining with DAPI was performed before photomicrography. Samples were photographed under a two-photon laser-scanning microscope (Zeiss LSM710 NLO; Carl Zeiss, Oberkochen, Germany) at $\times 630$ magnification.

\section{Electron Microscopy}

The sorted $\gamma \delta$ T cells were collected and fixed in $2.5 \%$ glutaraldehyde overnight, washed with $0.1 \mathrm{M}$ PBS ( $\mathrm{pH}$ 7.4) thrice, and post-fixed with $1 \%$ osmium tetroxide for $1 \mathrm{~h}$. For scanning electron microscopy (SEM), the cells were washed with PBS and dehydrated in graded acetone. The isoamyl acetate was used to replace the acetone before drying the sample. Then, samples were coated with a layer of gold before observation under SEM (HITACHI S-3000N) (26). For transmission electron microscopy (TEM), cells were embedded in graded Epon 812 after being 
washed with PBS and dehydrated in graded acetone and kept at $60^{\circ} \mathrm{C}$ for 2 days. Thin $(50-70 \mathrm{~nm})$ sections were prepared and stained with uranyl acetate (2\%) and lead citrate before observation under TEM (PHILIPSTECNAI10) (27).

\section{Western Blot Analysis}

Freshly dissected zebrafish spleen and head kidney tissues and sorted $\gamma^{+}$or $\delta^{+}$cells $\left(4 \times 10^{4}\right)$ were added to cold RIPA buffer. Samples were homogenized and incubated for $30 \mathrm{~min}$ on ice. Cell lysates were centrifuged at $10,000 \mathrm{~g}$ for $10 \mathrm{~min}$ at $4^{\circ} \mathrm{C}$. The protein content was quantified using the Bradford assay. Whole protein extracts or recombinant proteins were added to Laemmli loading buffer and incubated at $99^{\circ} \mathrm{C}$ for $10 \mathrm{~min}$. Samples were separated by $12 \%$ SDS-PAGE under reducing conditions. After blotting onto PVDF membranes, 5\% skimmed milk was used for blocking, and the membranes were incubated with primary Abs (anti- $\gamma$, anti- $\delta$, anti- $\alpha$, anti- $\beta$, anti-CD8 $\alpha$ ), followed by a secondary HRP-conjugated anti-rabbit/mouse IgG Ab $(1: 8,000)$. Immunoreactive proteins were visualized using a chemiluminescent immunodetection system (Tanon 4500).

\section{Tissue Distribution Analysis}

Tissue distribution of $\gamma \delta$ T cells in zebrafish was analyzed by the expression of DrTRGC and DrTRDC genes and the proportion of $\gamma^{+} / \delta^{+}$cells in tissues by real-time RT-PCR and FCM. For realtime RT-PCR, total RNAs were isolated from various tissues, including the head kidney, gill, spleen, liver, intestine, peripheral blood leukocyte (PBL), skin, heart, muscle, and brain. All PCR reactions were performed in a total volume of $10 \mu \mathrm{L}$ by using a SYBR Premix Ex Taq kit (Takara Bio). The relative expression levels were calculated using the $2^{-\Delta \Delta \mathrm{CT}}$ method with $\beta$-actin for normalization. Each PCR trial was performed in triplicate and repeated independently at least thrice. For FCM, leukocytes were isolated from the representative immune-relevant tissues, including the spleen, head kidney, skin, gill, intestine, and peripheral blood. The percentages of $\gamma^{+} / \delta^{+}$cells in these tissues were detected by FCM as described above.

\section{Phagocytosis Assay}

Freshly isolated $\gamma \delta \mathrm{T}$ cells $\left(4 \times 10^{4}\right)$ were incubated at $28^{\circ} \mathrm{C}$ with FITC-conjugated keyhole limpet hemocyanin (FITC-KLH; Sigma-Aldrich), red fluorescent latex beads (1 $\mu \mathrm{m}$; SigmaAldrich, L-2778) or FITC-labeled Aeromonas hydrophila (A.h) at a cell/bead ratio of 1:10. Cells in the control group for active phagocytosis were incubated on ice. After $4 \mathrm{~h}$, trypan blue $(200 \mu \mathrm{g} /$ $\mathrm{mL}$ ) was added to quench the fluorescence of KLH/beads/A.h that had not been internalized for $5 \mathrm{~min}$ at $4^{\circ} \mathrm{C}$. In parallel, $\gamma \delta$ $\mathrm{T}$ cells incubated with FITC-KLH, red fluorescent beads, and FITC-A.h $\left(28^{\circ} \mathrm{C}\right.$ for $\left.4 \mathrm{~h}\right)$ in the presence of cytochalasin B $(80 \mu \mathrm{g} /$ $\mathrm{mL}$; Sigma-Aldrich) were set as controls. Then, cells were washed thrice with PBS before FCM analysis.

\section{Function of $\gamma \delta \mathrm{T}$ Cells in CD4 ${ }^{+} \mathrm{T}$ Cell Activation In Vitro}

At 5 days before sacrifice, the fish (3-12 month) were immunized by i.p. injection with $10 \mu \mathrm{g}$ KLH in combination with $10 \mathrm{ng}$ LPS or
A.h $\left(2 \times 10^{7} \mathrm{CFU} /\right.$ fish $)$. Subsequently, Ag-stimulated CD4 ${ }^{+} \mathrm{T}$ cells were magnetically sorted from the blood, spleen, and head kidney, then stained with $5 \mu \mathrm{M}$ CFSE (Beyotime) for $8 \mathrm{~min}$ at room temperature. The reaction was terminated by supplementing with $10 \%$ FBS (in L-15 medium), and cells were washed thrice with the medium. The primary $\gamma \delta \mathrm{T}$ cells were isolated from untreated fish and fish stimulated with $10 \mu \mathrm{g}$ KLH (plus $100 \mathrm{ng}$ LPS or $2 \times 10^{7} \mathrm{CFU}$ A.h) for $8 \mathrm{~h}$ and washed thrice to eliminate noningested Ags. In the Ag-presentation inhibition control group, $\gamma \delta$ T cells were pretreated with chloroquine $(80 \mu \mathrm{M}$, Sigma-Aldrich) for $1 \mathrm{~h}$ and then incubated with Ags as described above. In the cross-stimulation control group, the KLH-pulsed $\gamma \delta$ T cells were co-cultured with CFSE-labeled $\mathrm{CD}^{+} \mathrm{T}_{\mathrm{A} . \mathrm{h}}$ cells. The $\mathrm{T}$ cell inhibitor cyclosporine A (CsA, $0.1 \mu \mathrm{g} / \mathrm{mL}$; Sigma-Aldrich) was used as a control. After 3 days of co-culture, the cells were labeled with primary mouse anti-CD4 Ab and secondary PE-conjugated antimouse IgG Ab. The proliferation of $\mathrm{CD} 4^{+} \mathrm{T}$ cells was examined through FCM based on the division of CFSE-labeled cells in $\mathrm{PE}-\mathrm{CD} 4^{+}$cell gate and analyzed by ModFit LT. The sample number for each group of fish exceeded 30, and all the experiments were conducted independently at least three times. The activation of $\mathrm{CD}^{+} \mathrm{T}$ cells was determined on the basis of the upregulation of Lck and CD154 through RT-PCR (21).

\section{Function of $\gamma \delta$ T Cells in CD4+ ${ }^{+}$Cell Activation In Vivo}

The fish were injected i.p. thrice with rabbit anti- $\gamma /$ anti- $\delta$ or nonspecific rabbit IgG (as control) at a dose of $10 \mu \mathrm{g} / \mathrm{fish}$, followed by administration of $\mathrm{Ag}(10 \mu \mathrm{g} \mathrm{KLH}$ plus $10 \mathrm{ng}$ LPS). At 3 days after the last Ag stimulation and Ab administration, the deletion level of $\gamma \delta$ T cells was examined through FCM. The activation of $\mathrm{CD} 4^{+} \mathrm{T}$ cells was evaluated by the percentage of $\mathrm{CD} 4^{+} \mathrm{CD} 154^{+}$ $\mathrm{T}$ cells in leukocytes from the peripheral blood, spleen, and head kidney, as determined using mouse anti-DrCD4 and rabbit antiDrCD154 primary Abs followed by FITC- and PE-conjugated anti-rabbit IgG and anti-mouse IgG secondary Abs through FCM. As a downstream event of $\mathrm{CD}^{+}{ }^{+} \mathrm{T}$ cell activation, the $\mathrm{B}$ cell activation was further examined on the basis of the percentage of $\mathrm{mIgM}^{+} \mathrm{CD} 40^{+} \mathrm{B}$ cells in leukocytes from the peripheral blood, spleen, and head kidney, as determined using mouse anti-DrIgM and rabbit anti-DrCD40 primary Abs followed by FITC- and PE-conjugated anti-rabbit IgG and anti-mouse IgG secondary Abs. The expression of Lck, CD154, mIgM, and CD40 was determined to evaluate the activation of $\mathrm{CD} 4^{+} \mathrm{T}$ cells and $\mathrm{B}$ cells through real-time PCR (11).

\section{Function of $\gamma \delta \mathrm{T}$ Cells in Ab Production}

Before the i.p. immunization with $\mathrm{KLH}(10 \mu \mathrm{g} /$ fish $)$ together with CFA, zebrafish were administered with anti- $\gamma / \delta$, or anti- $\alpha / \beta$ and $\operatorname{IgG}(10 \mu \mathrm{g} / \mathrm{fish})$ or CsA ( $5 \mu \mathrm{g} / \mathrm{fish})$ thrice at a $12 \mathrm{~h}$ time interval. The control groups received CFA in combination with mock PBS. The second immunization was given at 14 days. After 28 days of immunization, the serum and intestinal mucus were collected, the latter of which was dissolved in PBS ( $\mathrm{pH}$ 7.2) containing protease inhibitors $[1 \times$ protease inhibitor cocktail (Roche), 
$1 \mathrm{mM}$ phenylmethylsulfonyl fluoride (PMSF, Sigma), $0.1 \mathrm{mg} / \mathrm{mL}$ soybean trypsin inhibitor (Sigma), and 0.5\% BSA (Sigma)] and centrifuged at $400 \mathrm{~g}$ for $10 \mathrm{~min}$ to remove cell debris as previously described (28). The IgM and IgZ Abs against KLH were measured by ELISA (22). Ab titer is defined as the highest serum or mucus dilution at which the $\mathrm{A}_{450}$ ratio $\left(\mathrm{A}_{450}\right.$ of postimmunization sera/ $\mathrm{A}_{450}$ of preimmunization sera) is greater than 2.1.

\section{Adoptive Transfer Assays}

Three days before each immunization at days 1 and 14, the recipient fish were continuously injected with rabbit anti-DrMHC-II $\mathrm{Ab}$ thrice with a $12 \mathrm{~h}$ interval to eliminate APCs. In the same way, $\alpha \beta$ T cells of some recipient fish were eliminated by administering mouse anti- $\alpha$ and rabbit anti- $\beta$ thrice simultaneously. $\gamma \delta$ T cells were then magnetically sorted from the untreated fish and exposed to KLH (10 $\mu$ g plus $100 \mathrm{ng}$ LPS) for $8 \mathrm{~h}$. The cells in the control group were treated with mock PBS. The $\gamma \delta \mathrm{T}$ cells were washed thrice with L-15 medium to remove the free Ag and adjusted to $1 \times 10^{6} \mathrm{cell} / \mathrm{mL}, 1 \times 10^{7} \mathrm{cell} / \mathrm{mL}$, and $1 \times 10^{8}$ cell $/ \mathrm{mL}$. Afterward, $10 \mu \mathrm{L}$ of cell suspensions was i.p. injected into the recipient fish in different treatments along with the immunization with KLH.

\section{Statistical Analysis}

All data are presented as the mean \pm SD of each group. Statistical evaluation of differences between means of experimental groups was done by Student's $t$ tests. Statistical significance was considered at $P<0.05$ or $P<0.01$. The sample number for each group of fish exceeded 10. All experiments were replicated at least three times.

\section{RESULTS}

\section{Characterization of the Constant Regions of Zebrafish TCR- $\gamma$ and TCR- $\delta$}

Because the TCR- $\gamma /$ TCR- $\delta$ complex is a hallmark of $\gamma \delta$ T subset, we attempted to identify $\gamma \delta$ T cells in zebrafish using anti-zebrafish TCR- $\gamma$ and TCR- $\delta$ Abs. To produce these Abs, the cDNAs encoding the constant regions of zebrafish TCR- $\gamma$ (DrTRGC) and TCR- $\delta$ (DrTRDC) were identified for the design of antigen epitope peptides. The DrTRGC and DrTRDC cDNAs were cloned from spleen and intestinal tissues by using primers designed on the basis of the predicted sequences in NCBI (AY973884.1 and CAK05280.1). The cDNA of DrTRGC is 540 bp in length, with a 537 bp ORF that encodes 179 amino acids (GenBank accession number KX009744). The cDNA of DrTRDC is 471 bp in length, with a 468 bp ORF that encodes 156 amino acids (GenBank accession number KX009743; Figure S1 in Supplementary Material). The organizations of DrTRGC and DrTRDC genes were clarified by comparing the cDNAs of DrTRGC and DrTRDC with the corresponding genomic sequences. DrTRGC and DrTRDC genes contain three exons and two introns located within 3.09 and $1.05 \mathrm{~kb}$ genomic fragments on chromosome 2, respectively (Figure S2A in Supplementary Material). The genes adjacent to DrTRGC and DrTRDC clusters were retrieved by using Genscan and BLAST programs. According to the genes around the TRGC cluster on human chromosome 7 or mouse chromosome 13, epdr1, stard3nl, amph, and hecw1 genes were clustered on zebrafish chromosome 2, and they shared a highly conserved chromosome synteny with their human counterparts; however, the synteny of these genes was in converse orders between mice and humans (Figure S2B in Supplementary Material). Similarly, hnrnpc, chd8, tox4, sall2, and TRA around the TRDC clusters on human and mouse chromosomes 14 were also clustered around the DrTRDC loci on chromosome 2, although the synteny of these genes was in converse orders between zebrafish and humans or mouse (Figure S2B in Supplementary Material).

DrTRGC and DrTRDC proteins were predicted as membrane molecules with molecular weights of $\sim 20$ and $\sim 17 \mathrm{kDa}$, respectively. Both proteins exhibit hallmark TCR features: an immunoglobulin constant (Ig-C) domain (107 aa for DrTRGC and 103 aa for DrTRDC), a connecting peptide of varying lengths (38 aa for DrTRGC and 23 aa for DrTRDC), a transmembrane region (22 aa for DrTRGC and 20 aa for DrTRDC), and a cytoplasmic domain (11 aa for DrTRGC and 10 aa for DrTRDC). Multiple alignments show that the key functional amino acid residues in DrTRGC and DrTRDC proteins share a higher degree of homology with that of other species, which including $\mathrm{C}^{33}$ (first-Cys), $\mathrm{P}^{40}, \mathrm{~W}^{47}$, $\mathrm{C}^{93}$ (second-Cys) in the Ig-C domain of TRGC; $\mathrm{Y}^{172}, \mathrm{~K}^{178}$ in the transmembrane region of TRGC; $\mathrm{P}^{9}, \mathrm{C}^{33}$ (first-Cys), $\mathrm{F}^{38}, \mathrm{Y}^{73}, \mathrm{C}^{92}$ (second-Cys) in the Ig-C domain of TRDC, and $\mathrm{R}^{156}, \mathrm{~K}^{161}$ in the transmembrane region of TRDC (Figure S3 in Supplementary Material). $\mathrm{C}^{33}$ and $\mathrm{C}^{93}$ in DrTRGC and $\mathrm{C}^{33}$ and $\mathrm{C}^{92}$ in DrTRDC of the Ig-C domains, which are involved in an intra-chain disulfide bond, are highly conserved from fish to mammals. Another conserved cysteine is present in the connecting peptides of $\operatorname{DrTRGC}\left(\mathrm{C}^{129}\right)$ and DrTRDC $\left(\mathrm{C}^{128}\right)$. This cysteine likely forms an inter-chain disulfide bridge between the connecting peptides of TRGC and TRDC in mouse models. Moreover, a characteristic CX6PX6WX45C motif is found in the Ig-C domain of TRGC in all species. DrTRGC and DrTRDC, respectively, share 34-61\% and 34-39\% amino acid similarities with those of their mammalian counterparts. Phylogenetic analysis revealed that DrTRGC and DrTRDC were clustered independently from those of other fish and then merged with mammalian counterparts to form a solitary branch (Figure S4 in Supplementary Material). These findings demonstrated the molecular and functional conservations of TRGC and TRDC homologs from fish to mammals during vertebrate evolution.

\section{Identification of $\gamma \delta$ T Cells from Zebrafish}

Based on the above predicted structural information, the potential immunogenic epitope sequences of DrTRGC (a 17-aa peptide, $\mathrm{S}^{123}-\mathrm{Q}^{139}$ ) and $\operatorname{DrTRDC}$ (a 14 -aa peptide, $\mathrm{S}^{12}-\mathrm{C}^{25}$ ) chosen for immunization were located on the surface of a more exposed $\beta$-barrel structure in the extracellular Ig- $\mathrm{C}$ domains of the two molecules (Table S2 in Supplementary Material). Abs against DrTRGC and DrTRDC (namely anti- $\gamma$ and anti- $\delta$ ) were produced based on these epitope peptides from rabbit or mouse, respectively. ELISA demonstrated that the prepared Abs yielded an average titer of more than 1:10,000. Western blot revealed that the affinity-purified Abs have high specificities to the antigen proteins, as determined by their specific binding to the recombinant 
DrTRGC and DrTRDC proteins prepared from E. coli and to the corresponding endogenous proteins from spleen and head kidney tissues. To further demonstrate specificity, blocking peptides were also included in the WB analysis. Results showed the band signals weakened or disappeared when incubating with blocking peptides together with their corresponding Abs (Figures S5A-C in Supplementary Material). Minimal cross-reactions were detected between other TCRs (Figure S5A in Supplementary Material). In addition, three other Abs against zebrafish TCR- $\alpha$, TCR- $\beta$, and CD8 $\alpha$ (namely anti- $\alpha$, anti- $\beta$, and anti-CD8) required for experiment were also produced based on their epitope sequences in the extracellular domains of DrTRAC, DrTRBC, and CD8 $\alpha$, respectively (Table S2 in Supplementary Material).

Flow cytometry analysis of leukocytes from peripheral blood, head kidney, and spleen tissues using rabbit anti- $\gamma$ or mouse anti- $\delta \mathrm{Ab}$ alone showed a distinct $\gamma$ or $\delta$ single-positive cell population $\left(\gamma^{+}\right.$or $\left.\delta^{+}\right)$with a similar proportion of the total lymphoid cells (15.4 or 14.9\%), respectively (Figure 1A); and it also showed a distinct $\gamma$ and $\delta$ double-positive subset $\left(\gamma^{+} \delta^{+}\right)$ with a similar proportion (13.6\%) seen in $\gamma$ or $\delta$ single-positive population by co-staining the leukocytes with rabbit anti- $\gamma$ and mouse anti- $\delta$ Abs (Figure 1B). These $\gamma^{+} \delta^{+}$cells were also clearly detected in mixed leukocytes by double-immunofluorescence staining under a laser-scanning microscopy (Figures 1C,D). These $\gamma^{+} \delta^{+}$cells were further sorted from the mixed leukocytes by anti- $\gamma$ or anti- $\delta \mathrm{Ab}$-coated magnetic beads and subjected to cellular and molecular identification. Beforehand, the forward/side scatter (FSC/SSC) characteristics of the mixed leukocytes were examined through FCM, and result showed that three distinct scatter populations can be resolved by FSC/SSC analysis, whose profile was closely matched with those obtained from whole kidney marrow, in which major blood cell linages of lymphocytes $\left(\mathrm{FSC}^{\mathrm{int}} \mathrm{SSC}^{\mathrm{lo}}\right)$, precursors $\left(\mathrm{FSC}^{\text {hiSSC }} \mathrm{C}^{\mathrm{int}}\right)$, and myelomonocytes (FSC ${ }^{\text {hiSSC }}{ }^{\text {hi) }}$ ) were included (25). Then, the sorted $\gamma^{+} \delta^{+}$cells were subjected back to FSC/SSC analysis. Result showed that nearly all cells were enriched in the lymphocyte scatter population (FSC ${ }^{\text {int }} S C^{\text {lo }}$ gate), and they showed typical lymphocyte morphology by Wright-Giemsa staining (Figures 2B,D). Next, gene expression analysis was performed to show the independence of the sorted $\gamma^{+} \delta^{+}$subset from other cells by using a series of cellular hallmarks, including APC marker (MHC-II), T cell markers $(\gamma, \delta, \alpha, \beta, \mathrm{CD} 4$, and CD8), B cell marker (mIgM), and myeloid cell (monocyte/macrophage) markers (CSF-1R and FceRI), through RT-PCR. Result showed that either $\gamma^{+}$or $\delta^{+}$cells can express both $\delta$ and $\gamma$ transcripts; however, neither $\gamma^{+}$nor $\delta^{+}$cells express $\alpha, \beta$, mIgM, CSF-1R, and FceRI transcripts. This finding excludes $\alpha^{+} \beta^{+}$ $\mathrm{T}$ cells, $\mathrm{mIgM}^{+} \mathrm{B}$ cells, and monocytes/macrophages from the sorted $\gamma^{+} \delta^{+}$cells (Figure 2A). Moreover, immunoprecipitation and Western blot analyses further confirmed the expression of $\delta$ and $\gamma$ at protein levels in the sorted $\gamma^{+}$or $\delta^{+}$cells (Figure 2E), which also providing observation that $\gamma$ and $\delta$ proteins colocalized on $\gamma^{+} \delta^{+}$cells by the cross reactivity between the two proteins. In addition, cross double-immunofluorescence staining in $\gamma \alpha$ and $\delta \beta$ combinations showed few $\gamma \alpha$ and $\delta \beta$ double-positive $\left(\gamma^{+} \alpha^{+}\right.$and $\left.\delta^{+} \beta^{+}\right)$cells could be detected in the sorted $\gamma^{+} \delta^{+}$cells, which indicated that zebrafish $\gamma \delta \mathrm{T}$ cell is a distinct subset independent of $\alpha \beta$ T cells. Double-immunofluorescence staining by $\delta \mathrm{CD} 8$ and $\delta \mathrm{CD} 4$ showed considerable $\gamma$ - and $\delta$-positive cells exhibit $\mathrm{CD} 8$-positive $\left(\delta^{+} \mathrm{CD} 8^{+}\right)$and few $\delta \mathrm{CD} 4$ double positive $\left(\delta^{+} \mathrm{CD} 4^{+}\right)$existed (Figure 3). Detailed morphology of the $\gamma^{+} \delta^{+}$ cells were detected at approximately $5 \mu \mathrm{m}$ across, with round dense nuclei surrounded by a thin round ring of cytoplasm and numerous surface frills, as determined by TEM and SEM (Figure 2C). Finally, we analyzed the expression levels of DrTRGC and DrTRDC in different tissues and found that DrTRGC and DrTRDC were widely distributed in various lymphoid-associated tissues, such as spleen, head kidney, skin, gill, intestine, and PBLs, which was consistent with the performance of the lymphoid cells (Figure S6 in Supplementary Material). FCM results showed the $\gamma^{+} \delta^{+} \mathrm{T}$ cell population consisted of $7.7,9.3,16.9,18.3$, and $20.5 \%$ of the total lymphocytes in the spleen, head kidney, skin, gills, and intestinal tissues, respectively (Figure S7 in Supplementary Material). These results strongly indicated the existence of $\gamma \delta \mathrm{T}$ cell lineage in zebrafish, which exhibits phenotypic and morphological similarities to mammals.

\section{Phagocytic Capacity of Zebrafish $\gamma \delta$ T Cells}

The phagocytic capacity of $\gamma \delta \mathrm{T}$ cells was initially examined through FCM to evaluate the potential ability of zebrafish $\gamma \delta$ $\mathrm{T}$ cells acting as a kind of APCs in priming adaptive immunity. The $\gamma \delta$ T cells were magnetically sorted from the selected PBLs, spleens, and head kidney tissues and then examined to share a high degree of purity (>95\%) through FCM. The cells were incubated with FITC-KLH, $1 \mu \mathrm{m}$ red fluorescent latex beads (Sigma L2778-1ML), or FITC-A.h at $28^{\circ} \mathrm{C}$. The percentages of the phagocytic $\gamma \delta \mathrm{T}$ cells reached $14.76 \pm 1.06 \%$ (for FITC-KLH), $13.62 \pm 3.20 \%$ (for latex beads), and $7.45 \pm 1.05 \%$ (for FITCA.h), which were significantly higher than the $0.26 \pm 0.08 \%$, $0.24 \pm 0.07 \%$, and $0.33 \pm 0.11 \%$ for the corresponding control groups at $4^{\circ} \mathrm{C}$. Cytochalasin B treatment greatly inhibited FITC$\mathrm{KLH}$, latex beads, and FITC-A.h uptake by the $\gamma \delta \mathrm{T}$ cells. This finding indicated the $\gamma \delta \mathrm{T}$ cells could phagocytose substances in an actin polymerization-dependent manner. The enhanced amounts of Ag phagocytosis by $\gamma \delta$ T cells were also determined on the basis of the mean fluorescence intensity of FITC and red fluorescence (Figure 4A). Immunofluorescence confirmed that the red beads were indeed inside the cells (Figure 4B). Thus, zebrafish $\gamma \delta$ T cells exhibit potent non-specific phagocytic abilities for both soluble and particulate antigens.

\section{Function of Zebrafish $\gamma \delta$ T Cells in CD4 ${ }^{+}$ T Cell Activation In Vitro}

An in vitro antigen-specific $\mathrm{CD} 4^{+} \mathrm{T}$ cell activation assay was performed to investigate whether zebrafish $\gamma \delta \mathrm{T}$ cells can act as APCs to initiate adaptive immunity. The distribution of MHC-II, CD80/86, and CD83, three specific APC markers involved in $\mathrm{Ag}$ presenting and costimulatory signaling to $\mathrm{CD} 4^{+}$ $\mathrm{T}$ cells, were determined in the activated $\gamma \delta$ T cells magnetically sorted from the antigen (KLH)-stimulated fish through RT-PCR and double-immunofluorescence staining (Figures 5A,B). As expected, MHC-II, CD80/86, and CD83 were clearly expressed on the surfaces of the activated $\gamma \delta \mathrm{T}$ cells, and their expression 

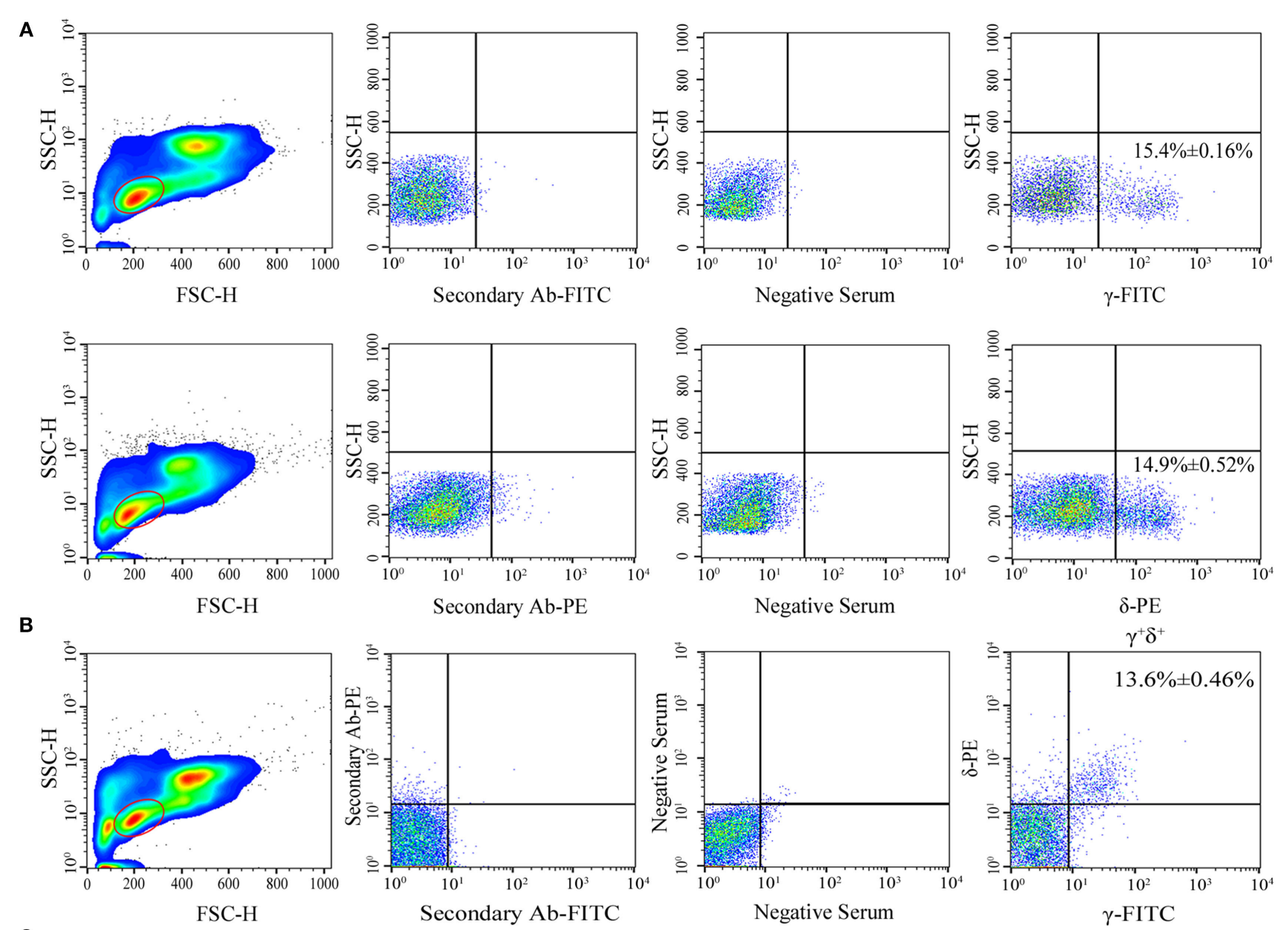

C
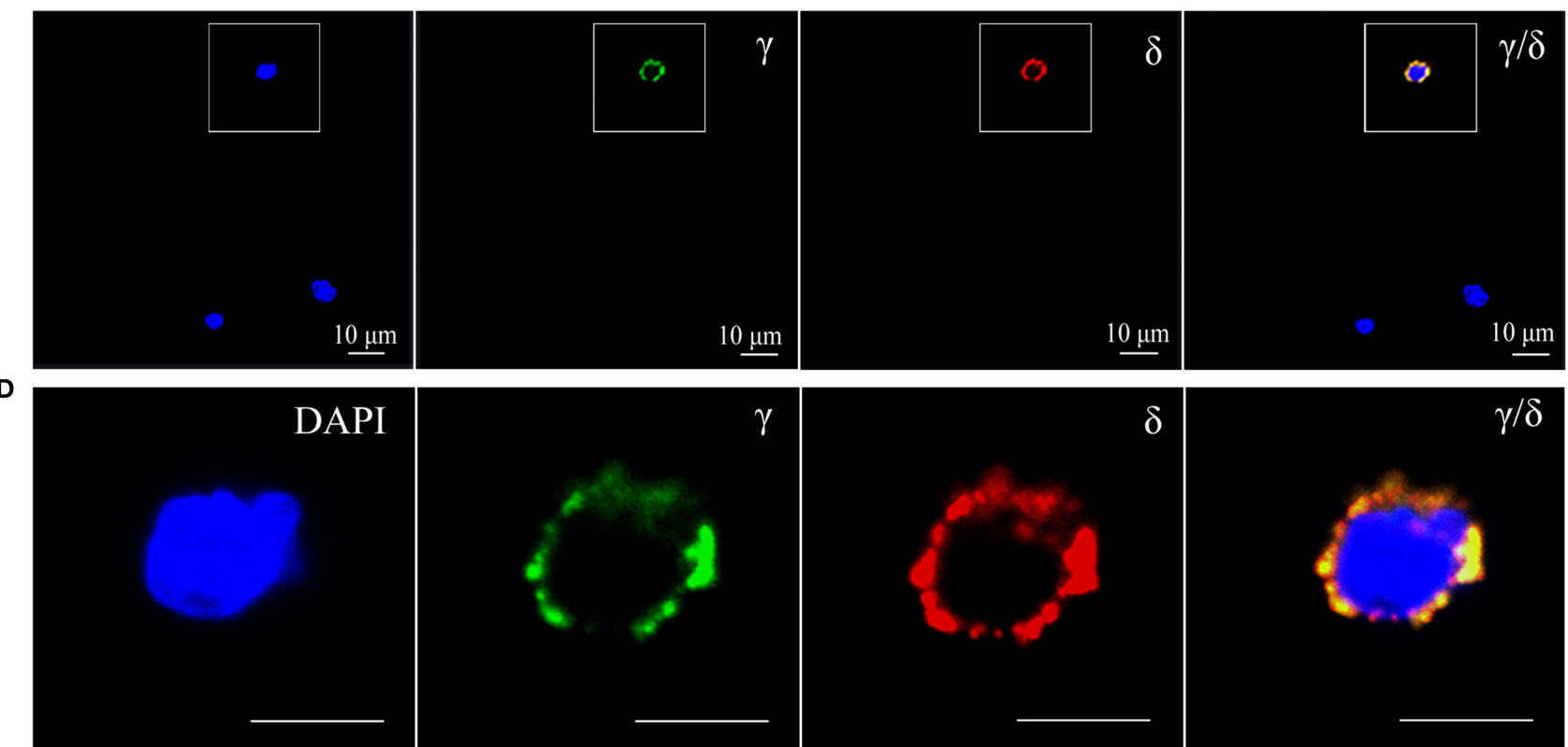

$\delta$

$\gamma / \delta$

FIGURE 1 | Flow cytometry (FCM) and immunofluorescence analyses of $\boldsymbol{\gamma}^{+} \boldsymbol{\delta}^{+}$cells in zebrafish. 
FIGURE 1 Continued

(A) FCM detection of $\gamma$ and $\delta$ single-positive $\left(\gamma^{+}\right.$and $\left.\delta^{+}\right)$cells in leukocytes from zebrafish peripheral blood, head kidney, and spleen tissues, respectively. The left panels show FSC/SSC analyses and the red-outlined gates represent lymphoid cells. Middle panels represent the cells treated only with the secondary Ab (FITC-conjugated goat anti-rabbit IgG or PE-conjugated goat anti-mouse IgG) and with the preimmunization serum. The right panels represent staining of cells with rabbit anti- $\gamma$ or mouse anti- $\delta$ Abs. (B) FCM detection of $\gamma \delta$-double positive $\left(\gamma^{+} \delta^{+}\right)$cells in leukocytes from zebrafish peripheral blood, head kidney, and spleen tissues. FSC/SSC analyses are shown in the left panel and red-outlined gate represents lymphoid cells. The middle panel shows the analysis of cells incubated only with secondary Abs and with the preimmunization serum. The right panel represents double staining of cells with rabbit anti- $\gamma$ and mouse anti- $\delta$ Abs. (C) Confocal microscopy image of $\gamma^{+} \delta^{+}$cells stained with rabbit anti- $\gamma$ and mouse anti- $\delta$ Abs. Non-related Abs, including mouse lgG and rabbit lgG, were used as negative controls (data not shown). DAPI stain showed the locations of the nuclei. A laser-scanning confocal microscopy (Zeiss LSM-710) was used in the analyses (original magnification $\times 630$, scale bar, $10 \mu \mathrm{m}$ ). (D) Enlarged images of $\gamma^{+} \delta^{+}$cells in the white-outlined square of E. Scale bar, $5 \mu \mathrm{m}$.
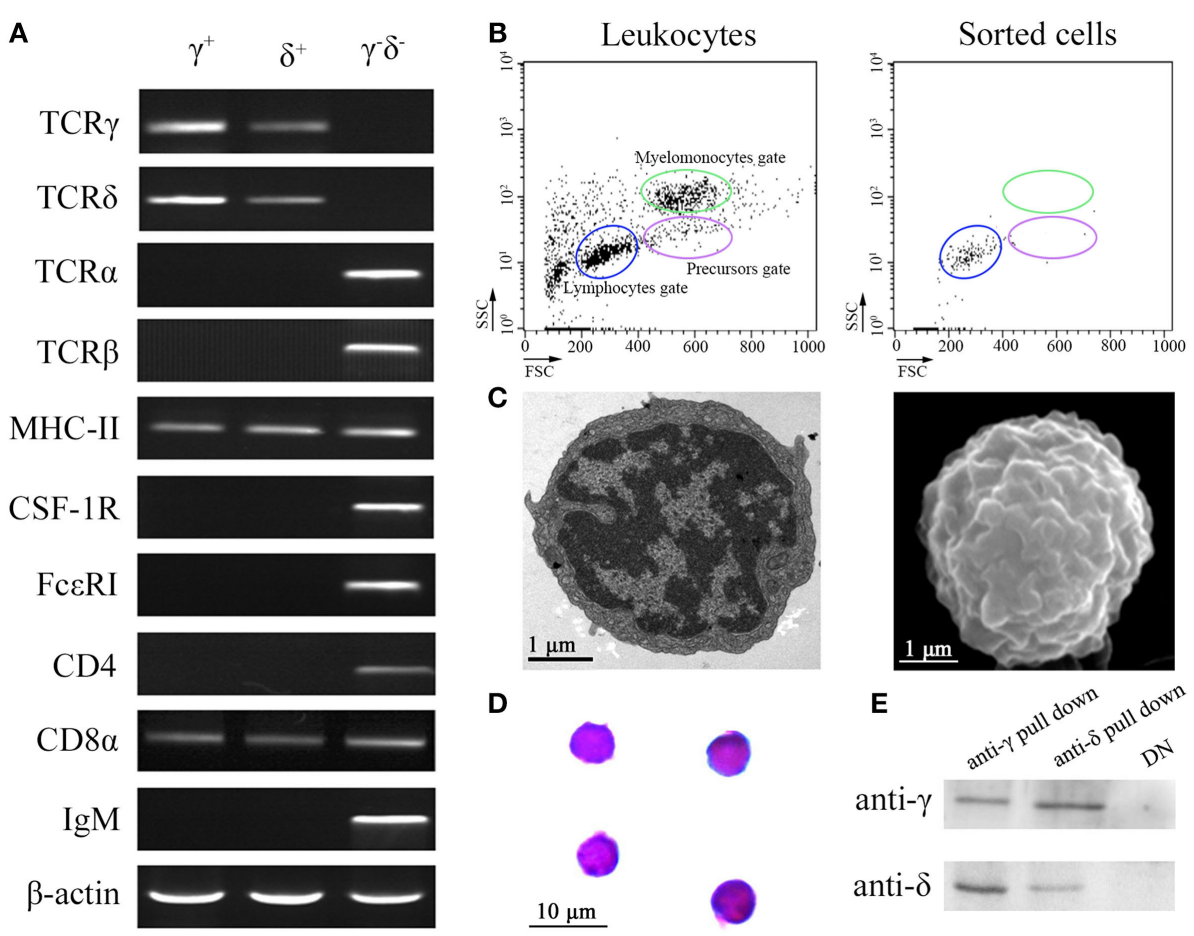

FIGURE 2 | Cellular and molecular identification of zebrafish $\boldsymbol{\gamma} \boldsymbol{\delta} \mathbf{T}$ cells. (A) RT-PCR assay analyzed the expression of T cell markers $(\gamma, \delta$, $\alpha$, $\beta$, CD4, and CD8), antigen-presenting cell marker (MHC-II), B cell marker (mlgM), and myeloid cell (monocyte/macrophage and dendritic cell) markers (CSF-1R and FcERI). The expressions of these markers from negative selection cells were used as control. (B) FCM analyzed the FSC/SSC profiles of leukocytes and the sorted cells. (C) Transmission electron microscopy and scanning electron microscopy show the detailed morphologies of sorted $\gamma \delta \mathrm{T}$ cells. Scale bar $1 \mu \mathrm{m}$ (bottom left). (D) Wright-Giemsa staining indicates the morphologies of the sorted $\gamma \delta \mathrm{T}$ cells. Scale bar $10 \mu \mathrm{m}$ (bottom left). Original magnification $\times 1,000$. (E) Detect the expressions of $\gamma$ and $\delta$ in the anti- $\gamma$ and anti- $\delta$ pull down cells, respectively, by Western blot.

was significantly upregulated in response to Ag stimulation (Figure 5A). This finding provides initial evidence that zebrafish $\gamma \delta \mathrm{T}$ cells exhibit the functional characteristics of APCs. For the $\mathrm{T}$ cell activation assay, the siblings generated from the same lineage after five generations of inbreeding were used to lessen the potential allogenic reactions as much as possible, because the pure inbred zebrafish lines are difficult to create due to inbreeding depression $(21,25,29)$. The primary $\gamma \delta \mathrm{T}$ cells that were sorted from non-stimulated fish were boosted in vitro by KLH in combination with LPS, a pathogen-associated molecular pattern expected to provide a costimulatory signal, and then co-cultured with the KLH-stimulated $\mathrm{CD}^{+}{ }^{+} \mathrm{T}$ cells $\left(\mathrm{CD} 4^{+} \mathrm{T}_{\mathrm{KLH}}\right)$ isolated from the fish in vivo administrated with KLH. Expectedly, KLHloaded $\gamma \delta \mathrm{T}$ cells remarkably enhanced the cognate $\mathrm{CD} 4^{+} \mathrm{T}_{\mathrm{KLH}}$ cell proliferation by approximately 4.5 -fold compared with the mock PBS-loaded $\gamma \delta$ T cell controls. Next, an Ag-presentationinhibition assay and a cross-stimulation experiment were further performed to exclude the potential allogenic reactions. Results showed that $\mathrm{CD} 4^{+} \mathrm{T}_{\mathrm{KLH}}$ cell response was remarkably decreased by incubating KLH-loaded $\gamma \delta \mathrm{T}$ cells with chloroquine, an inhibitor of endosomal and lysosomal acidifications and proteolyses required for MHC-II-mediated antigen presentation. $A$. $h$-pulsed $\gamma \delta$ T cells elicited considerably less effects on the increase in $\mathrm{CD}^{+}$ $\mathrm{T}_{\mathrm{KLH}}$ proliferation than KLH-pulsed $\gamma \delta \mathrm{T}$ cells did. The $\mathrm{CD}^{+}$ 


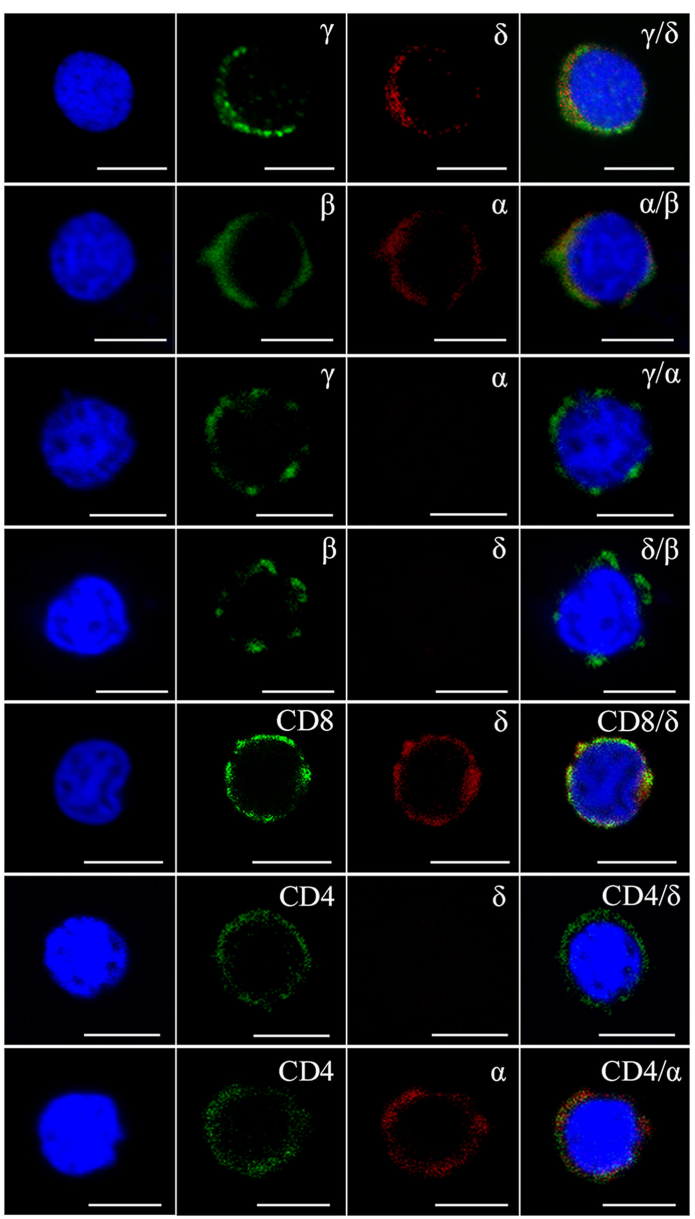

FIGURE 3 | Immunophenotype analysis of zebrafish $\gamma \delta$ T cells by Abs against various surface molecules. The magnetic sorted cells were double stained with anti- $\gamma$, anti- $\delta$, anti- $\alpha$, anti- $\beta$, anti-CD8, and anti-CD4 Abs in different combinations (rabbit anti- $\gamma /$ mouse anti- $\delta$, rabbit anti- $\beta /$ mouse anti- $\alpha$, rabbit anti- $\gamma /$ mouse anti- $\alpha$, rabbit anti- $\beta /$ mouse anti- $\delta$, rabbit anti-CD8/ mouse anti- $\delta$, rabbit anti-CD4/mouse anti- $\delta$, and rabbit anti-CD4/mouse anti- $\alpha$, respectively). Positive control cells were stained with rabbit anti- $\beta$ and mouse anti- $\alpha$ Abs. Non-related Abs, including mouse lgG and rabbit lgG, were used as negative controls (data not shown). DAPI stain showed the locations of the nuclei. A laser-scanning confocal microscopy (Zeiss LSM-710) was used in the analyses (original magnification $\times 630$, scale bar, $5 \mu \mathrm{m})$.

$\mathrm{T}_{\mathrm{KLH}}$ cell proliferation was also significantly decreased by CsA, an inhibitor of thymus-dependent T cell activation (Figure $5 \mathrm{C}$ ). These results suggested that the Ag-specific reaction largely contributes to the major proliferation of $\mathrm{CD} 4^{+} \mathrm{T}$ cells. Besides, the activation of $\mathrm{CD} 4^{+} \mathrm{T}_{\mathrm{KLH}}$ cells stimulated by KLH-activated $\gamma \delta$ $\mathrm{T}$ cells was also examined by the increased expression of Lck and CD154 (Figure 5D). Collectively, the above results demonstrated that zebrafish $\gamma \delta$ T cells can act as powerful APCs.

\section{Function of Zebrafish $\gamma \delta$ T Cells in CD4 ${ }^{+}$ T Cell Activation In Vivo}

An in vivo depletion assay was performed to obtain additional evidence supporting the involvement of zebrafish $\gamma \delta \mathrm{T}$ cells in priming Ag-specific $\mathrm{CD}^{+} \mathrm{T}$ cells. The fishes received anti- $\gamma$ or anti- $\delta$ Abs, and the amounts of $\gamma \delta$ T cells decreased by approximately $50 \%$ lower than those of the PBS- or non-related rabbit IgG-treated fishes (Figure 6A). Compared with that of the antigen (KLH)-immunized control groups, the proportion of the activated $\mathrm{CD}^{+}{ }^{+} \mathrm{T}_{\mathrm{KLH}}$ cells $\left(\mathrm{CD} 4{ }^{+} \mathrm{CD} 154^{+} \mathrm{T}_{\mathrm{KLH}}\right)$ decreased from $12.38 \pm 0.27 \%$ to $6.17 \pm 0.79 \%$ in the $\gamma \delta \mathrm{T}$ cell-depleted groups Compared with those of the normal KLH-immunized groups, the percentages of $\mathrm{CD} 4^{+} \mathrm{CD} 154^{+} \mathrm{T}_{\mathrm{KLH}}$ cells $(11.33 \pm 0.81 \%)$ did not significantly decrease in the non-related IgG-treated groups (Figure 6B). Similarly, the expression levels of Lck and CD154 upon KLH stimulation in PBLs and head kidney leukocytes (HKLs) were remarkably $(P<0.01)$ downregulated in the $\gamma \delta$ $\mathrm{T}$ cell-depleted groups (Figure 6C). These results provided in vivo evidence that zebrafish $\gamma \delta \mathrm{T}$ cells play an essential role in Ag-specific $\mathrm{T}$ cell activation in the initiation of adaptive immunity.

\section{Function of Zebrafish $\gamma \delta$ T Cells in B Cell Activation and IgM Production}

Next, in vivo B cell activation and IgM production assays were performed for further determination of the functions of zebrafish $\gamma \delta \mathrm{T}$ cells in the initiation of adaptive immunity. Compared with those of the Ag-immunized normal group, the $\operatorname{IgM}^{+}$ $\mathrm{CD}_{40}{ }^{+} \mathrm{B}$ cells in the $\gamma \delta \mathrm{T}$ cell-depleted group decreased from $23.35 \pm 0.66 \%$ to $14.68 \pm 1.08 \%$ when the cells were injected with KLH combined with LPS. By contrast, the percentage of $\mathrm{IgM}^{+} \mathrm{CD} 40^{+} \mathrm{B}$ cells did not significantly decrease in the nonrelated IgG-treated group compared with that in the normal immunized group (Figure 7A). The expression levels of IgM and CD40 in PBLs and HKLs were remarkably downregulated in the $\gamma \delta \mathrm{T}$ cell-depleted group (Figure 7B). The production of the systematic IgM against KLH in the serum of $\gamma \delta \mathrm{T}$ celldepleted group decreased significantly compared with that of KLH-immunized control group. This finding was similar to $\alpha \beta$ T cell-depleted group that served as a positive control treated with anti- $\alpha$ and anti- $\beta$ Abs. However, the production of IgM in nonrelated IgG-treated control groups did not decrease significantly (Figure 7C). These results confirmed the function of zebrafish $\gamma \delta \mathrm{T}$ cells in the initial $\mathrm{CD}^{+} \mathrm{T}$ cell activation, subsequent $\mathrm{B}$ cell proliferation, and $\mathrm{Ab}$ production during the complete activation of adaptive immunity. An adoptive transfer assay was performed to further validate this finding. The generated sibling recipient fish were administered with anti-MHC-II antibody thrice to eliminate the basal MHC- $\mathrm{II}^{+} \mathrm{APCs}$ in vivo. With this method, the role of $\gamma \delta \mathrm{T}$ cells can be evaluated. The amount of $\mathrm{MHC}^{+}$ APCs in the depletion group was reduced by approximately $57 \%$ compared with that in the PBS- or non-related rabbit IgGtreated control groups (Figure $\mathbf{8 A}$ ). The double elimination of MHC-II ${ }^{+}$APCs and $\alpha \beta$ T cells (reduced $\sim 60 \%$, Figure 8A) was also conducted by co-administering anti-MHC-II with anti- $\alpha$, and anti- $\beta$ Abs in the recipient fish. The sorted primary $\gamma \delta$ $\mathrm{T}$ cells were then loaded in vitro with $\mathrm{KLH}$ and transferred into the KLH-stimulated sibling recipient fish. The decreased production of antigen-specific IgM secondary to the depletion of $\mathrm{MHC}-\mathrm{II}^{+}$ APCs was optimally recovered by transferring KLH-activated $\gamma \delta$ $\mathrm{T}$ cells in a dose-dependent manner. By contrast, no significant 

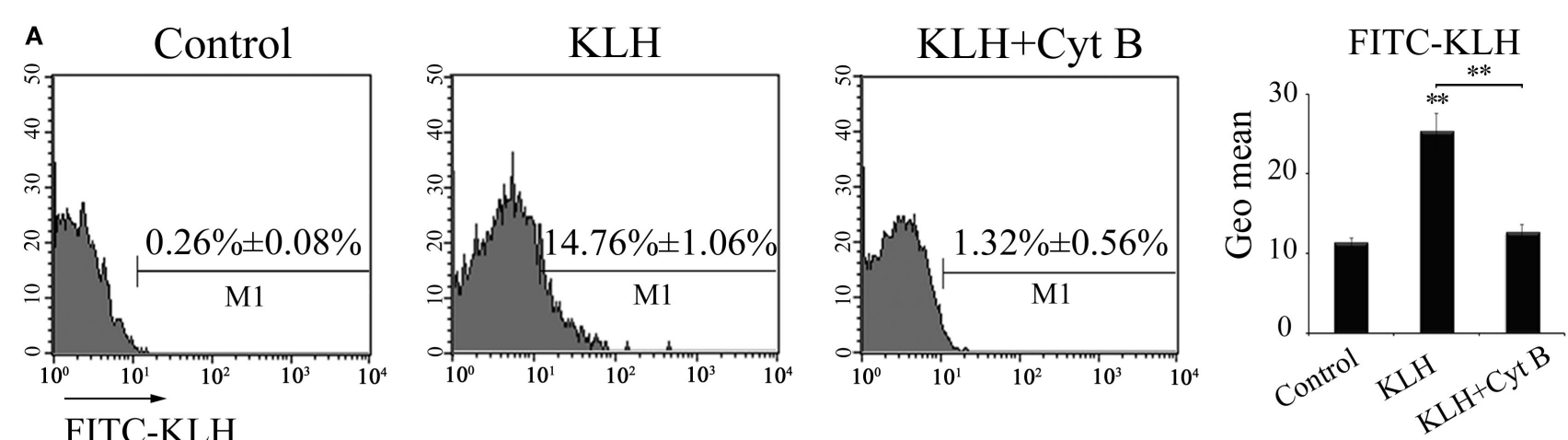

Control

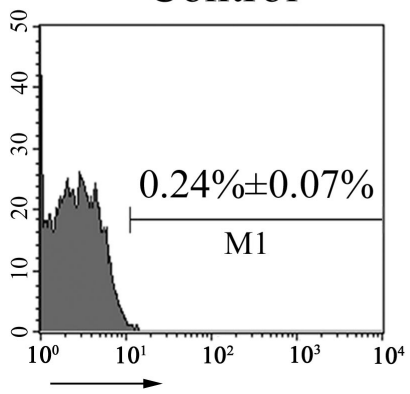

Red fluorescent beads

Control

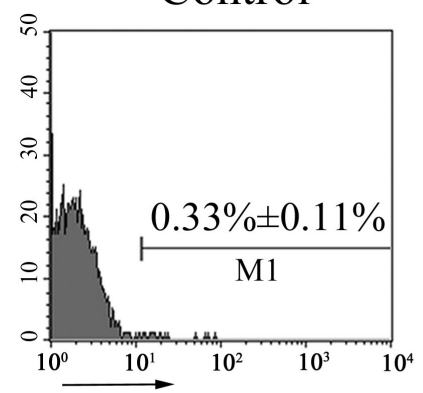

FITC-A.h

B

DAPI
Beads

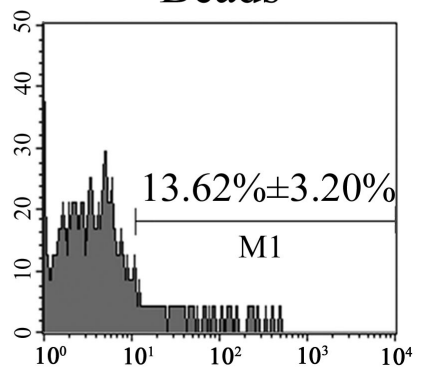

A.h

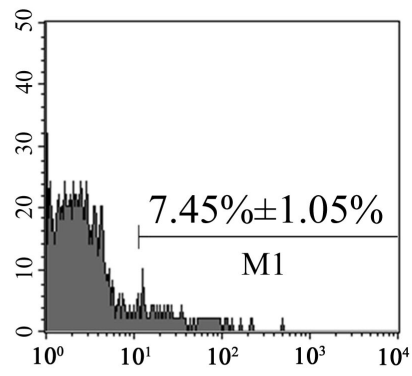

$\gamma$
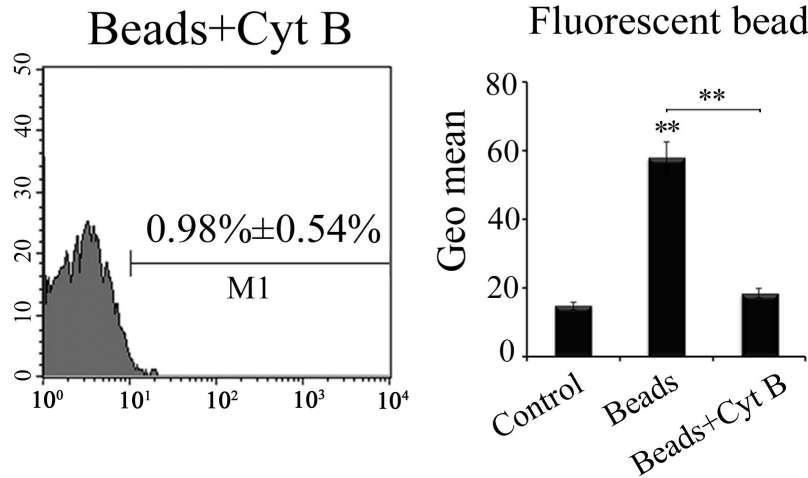

A.h + Cyt B

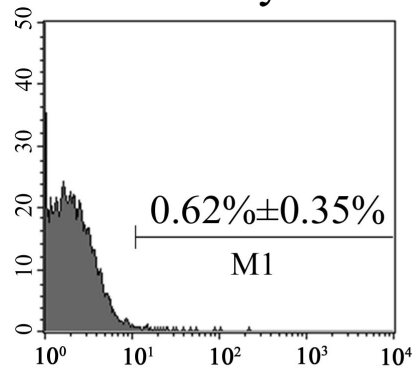

Beads

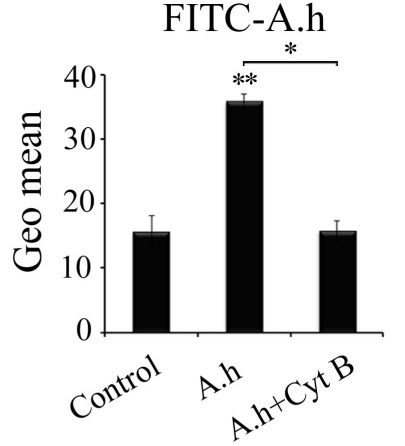

$\gamma /$ Beads
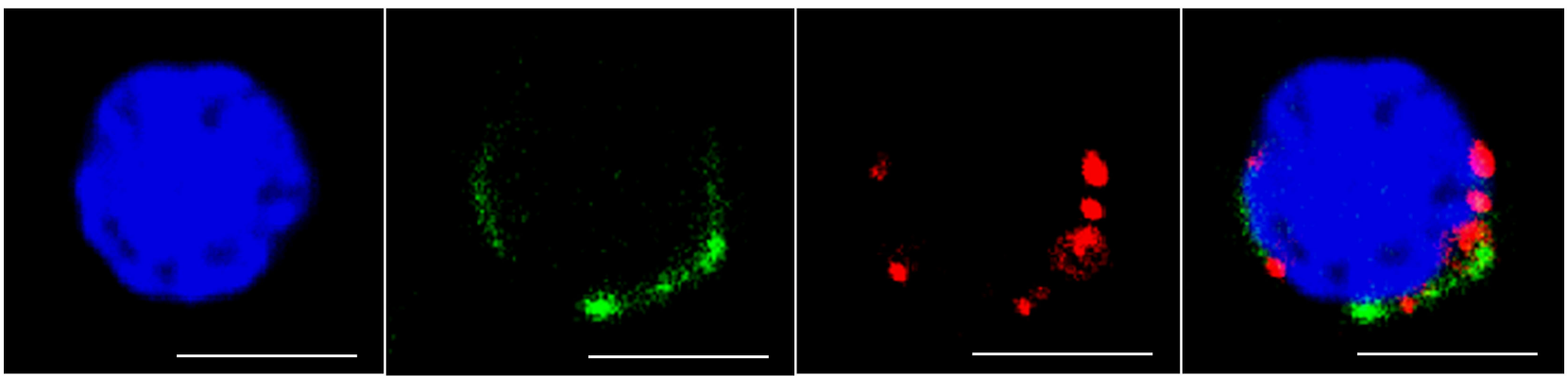

FIGURE 4 | Phagocytic ability of zebrafish $\boldsymbol{\gamma} \boldsymbol{\delta}$ T cells. (A) FCM detected the phagocytic ability. $\gamma \delta$ T cells were magnetically sorted and incubated with FITC-KLH, $1 \mu \mathrm{m}$ red fluorescent latex beads or FITC-A.h at $28^{\circ} \mathrm{C}$ for $4 \mathrm{~h}$. Cells in control group for active phagocytosis were incubated in ice. In parallel, $\gamma \delta \mathrm{T}$ cells incubated with FITC-KLH, red fluorescent beads, and FITC-A.h $\left(28^{\circ} \mathrm{C}\right.$ for $\left.4 \mathrm{~h}\right)$ in the presence of cytochalasin B were set as controls. The numbers above the marker bars in each panel indicate the percentages of phagocytic $\gamma \delta T$ cells. The geometric means of the fluorescence intensities computed from the outlined region represent the phagocytic ability of $\gamma \delta T$ cells in each treatment group. Means \pm SD of three independent experiments are shown. ${ }^{\star} P<0.05$, ${ }^{\star \star} P<0.01$. (B) Confocal microscopy of $1 \mu \mathrm{m}$ red fluorescent latex beads by $\gamma \delta \mathrm{T}$ cells. DAPI stain showed the location of the nuclei. Original magnification $\times 630$. Scale bar, $5 \mu \mathrm{m}$. 

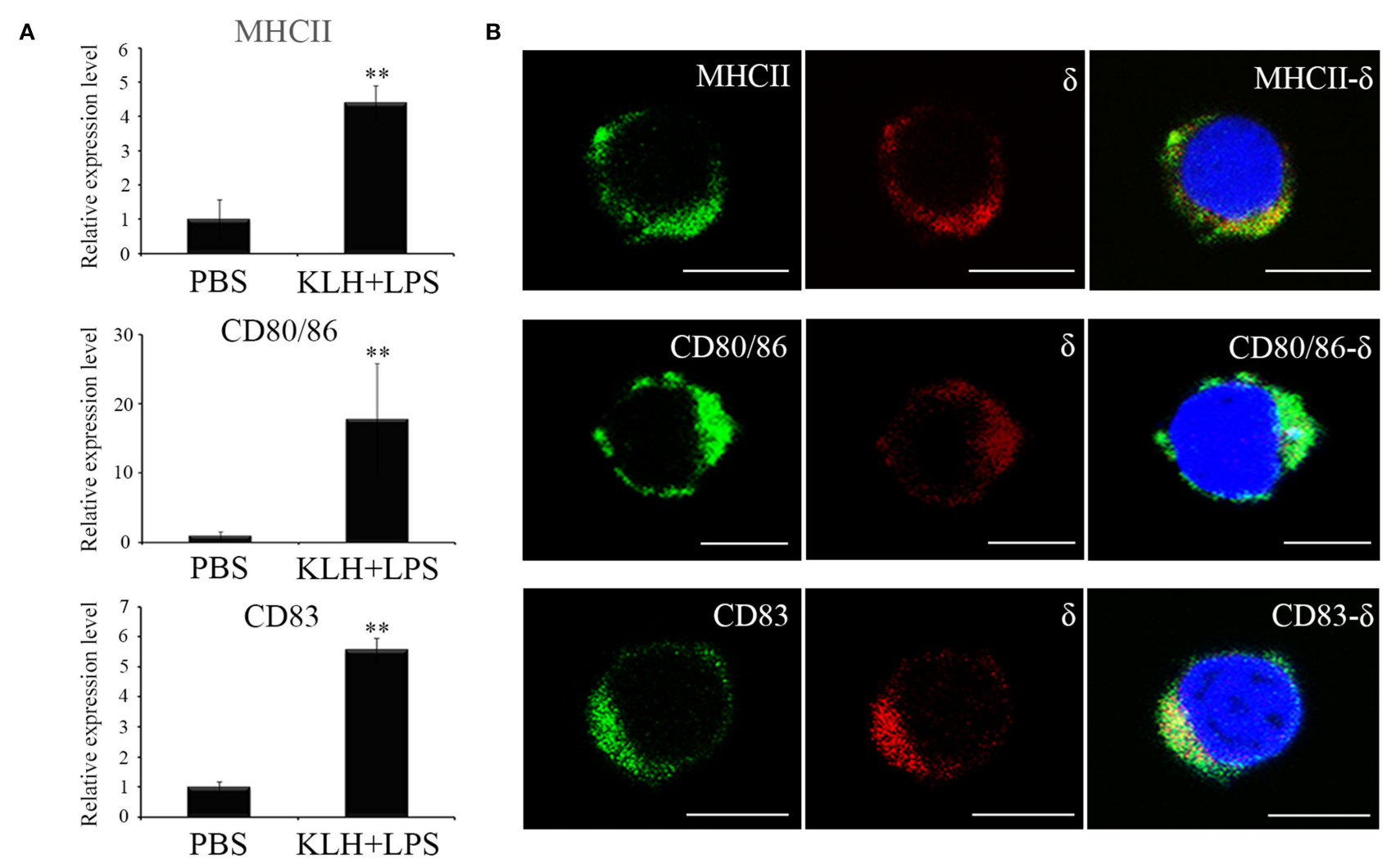

C

PBS $-\gamma \delta \mathrm{T} / \mathrm{T}_{\mathrm{KLH}} \quad \mathrm{KLH}+\mathrm{LPS}-\gamma \delta \mathrm{T} / \mathrm{T}_{\mathrm{KLH}} \quad \mathrm{KLH}+\mathrm{LPS}-\gamma \delta \mathrm{T} / \mathrm{T}_{\mathrm{KLH}}+\mathrm{Cs} A \quad \mathrm{KLH}+\mathrm{LPS}+\mathrm{Chl}-\gamma \delta \mathrm{T} / \mathrm{T}_{\mathrm{KLH}}$
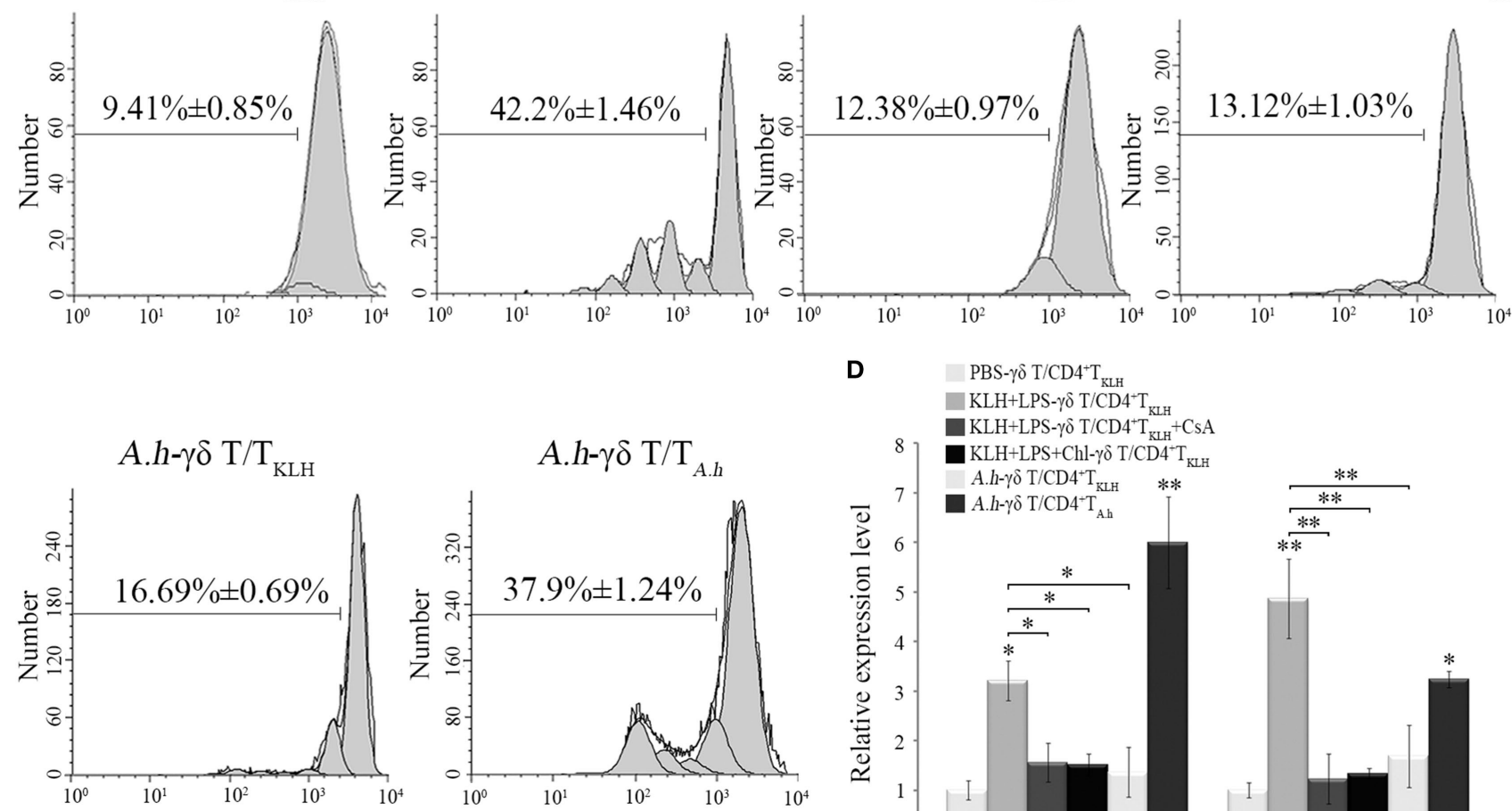

CFSE

D $\quad$ PBS- $\gamma \delta \mathrm{T} / \mathrm{CD} 4^{+} \mathrm{T}_{\mathrm{KLH}}$

KLH+LPS- $\gamma \delta$ T/CD4 ${ }^{+} \mathrm{T}_{\mathrm{KL}}$

KLH+LPS- $\gamma \delta \mathrm{T} / \mathrm{CD}^{4}{ }^{+} \mathrm{T}_{\mathrm{KLH}}+\mathrm{CsA}$

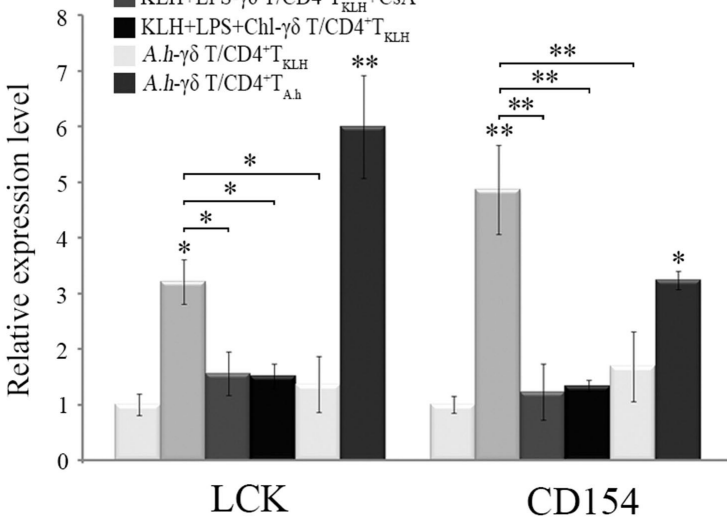

FIGURE 5 | In vitro evaluation of Ag-presenting capacity of zebrafish $\gamma \delta$ T cells. 
FIGURE 5 | Continued

(A) Real-time PCR analyses of the expression levels of MHC-II, CD80/86, and CD83 in PBS- and KLH, plus LPS-loaded $\gamma \delta$ T cells in vitro. (B) Immunofluorescence staining of $\delta^{+} \mathrm{MHC}^{+}, \delta^{+} \mathrm{CD} 80 / 86^{+}$, and $\delta^{+} \mathrm{CD} 83^{+}$cells. Leukocytes were stained with mouse anti- $\delta$ and rabbit anti-MHCll, CD83, and CD80/86, respectively. Non-related Abs, including mouse lgG and rabbit lgG, were used as negative controls (data not shown). DAPI stain showed the locations of the nuclei. Original magnification $\times 630$. Scale bar, $5 \mu \mathrm{m}$. (C) The proliferation and activation of CD4 ${ }^{+} \mathrm{T}_{\mathrm{KLH}}$ cells primed by Ag-loaded $\gamma \delta \mathrm{T}$ cells were determined after CFSE dilution and measured via FCM. The proliferation of CD4 ${ }^{+} \mathrm{T}_{\mathrm{KLH}}$ cells primed by mock PBS-treated $\gamma \delta \mathrm{T}$ cells served as a negative control. Cyclosporine A was used for the $T$ cell inhibitor control. For the Ag-presentation inhibition control, $\gamma \delta \mathrm{T}$ cells was pretreated with Chloroquine for $1 \mathrm{~h}$ and then incubated with Ags. In cross-stimulation control group, the $\mathrm{KLH}$-pulsed $\gamma \delta \mathrm{T}$ cells were co-cultured with CFSE-labeled CD4+ $\mathrm{T}_{\mathrm{A} . \mathrm{h}}$ cells. The numbers above the marker bars indicate the percentage of CFSE-diluted cells in each panel. Data represent three independent experiments. (D) The expression levels of Lck and CD154 were detected through real-time PCR. Means \pm SD of three independent experiments are shown. ${ }^{\star} P<0.05,{ }^{\star \star} P<0.01$.

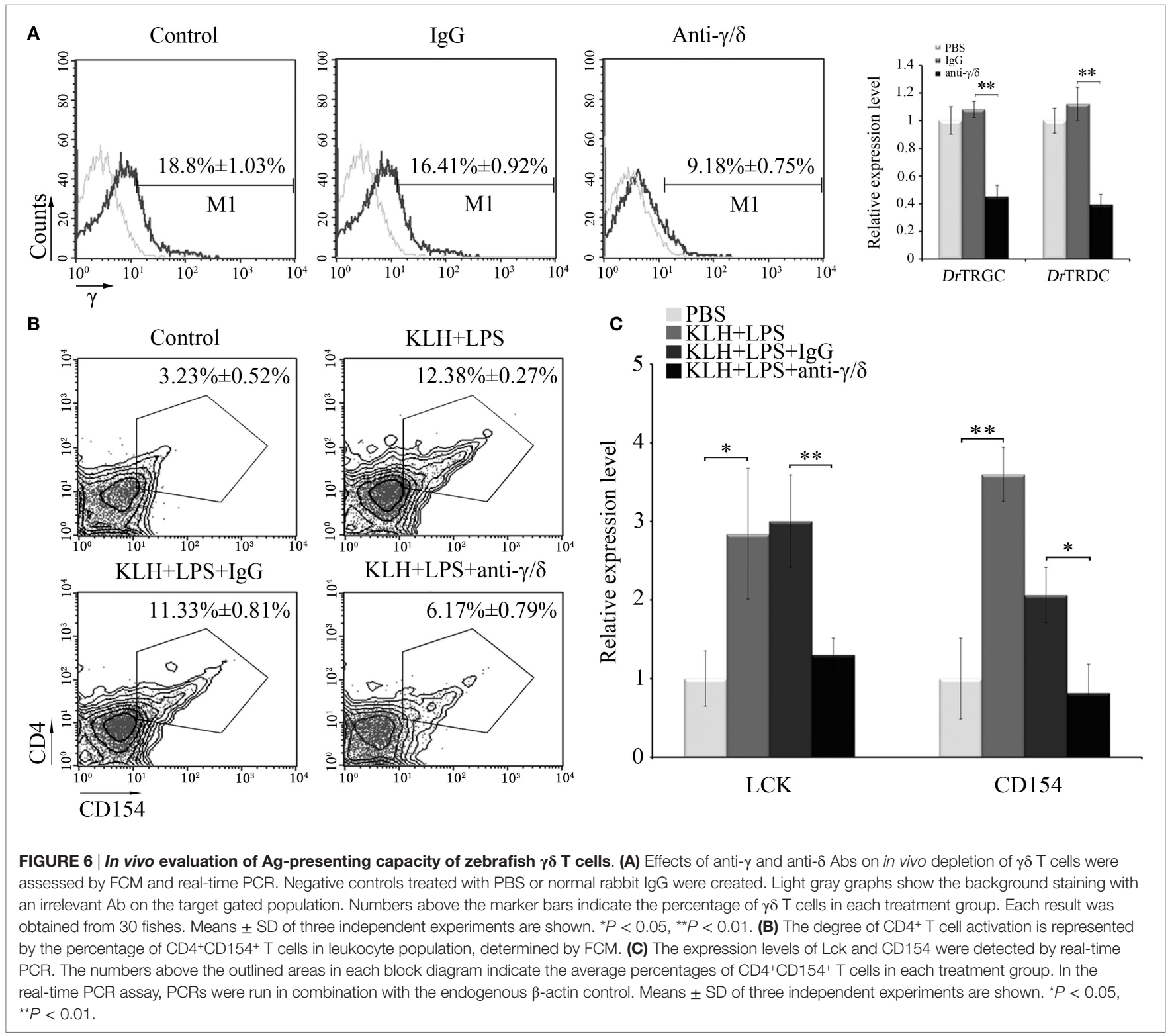

improvement was observed through the transfer of inactivated $\gamma \delta$ T cells (Figures 8B,C). Moreover, the decrease in IgM via the double depletion of MHC-II ${ }^{+}$APCs plus $\alpha \beta$ T cells was no longer restored by transferring either activated or inactivated $\gamma \delta$ T cells. Therefore, $\gamma \delta$ T cells contributed to antigen-specific IgM production in $\alpha \beta$ T cell-dependent pathways. 


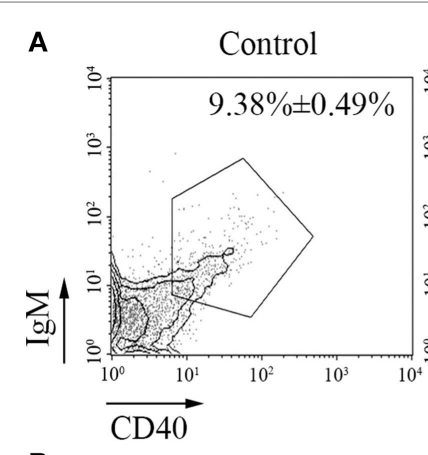

B

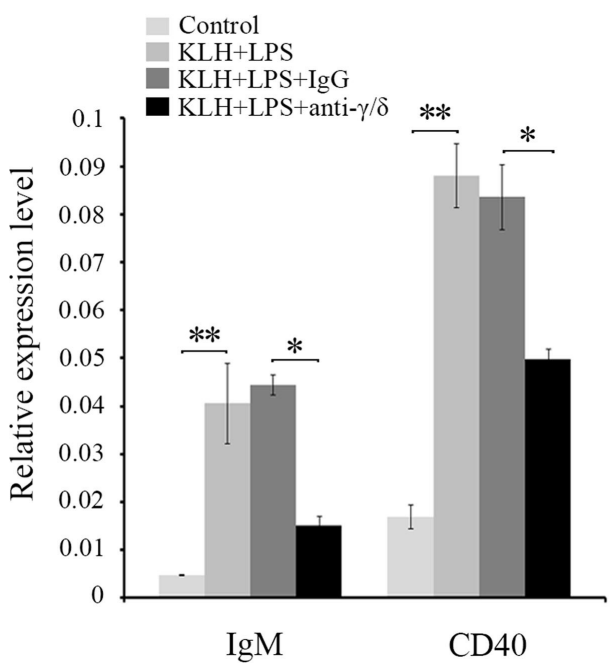

C

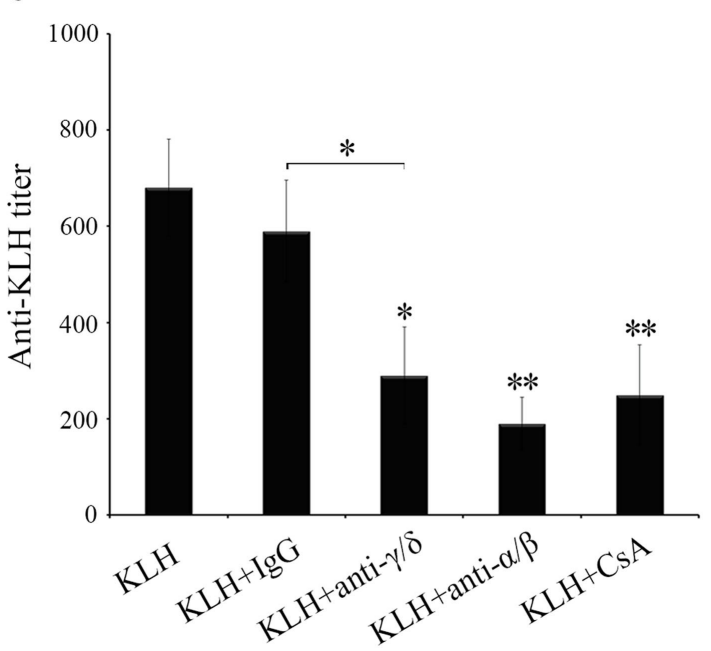

FIGURE 7 | In vivo evaluation of zebrafish $\boldsymbol{\gamma} \boldsymbol{\delta} \mathbf{T}$ cells in B cell activation and IgM production. The degree of B cells activation is represented by the percentage of mlgM+CD40+ B cells measured by FCM and by the expression levels of IgM and CD40 detected by real-time PCR (A,B). In the flow cytometric analysis, different treatments are shown at the top of each block diagram. The data above the outlined area indicate the average percentages of $\mathrm{mlgM}+\mathrm{CD} 4 \mathrm{O}^{+} \mathrm{B}$ cells in each treatment group. In the real-time PCR assay, PCRs were run in combination with the endogenous $\beta$-actin control. Means \pm SD of three independent experiments are shown. ${ }^{\star} P<0.05$, ${ }^{\star \star} P<0.01$. (C) The titers of IgM against $\mathrm{KLH}$ in each treatment group were examined by ELISA. The control groups immunized with KLH only. All of the groups were titered from 1/100 to 1/800, and the titer was ascertained based on the highest serum dilution at which the A450 ratio (A450 of postimmunization sera/A450 of preimmunization sera) is $\geq 2.1$. The data of the background control group with PBS administration were subtracted from each experimental group.

\section{$\gamma \delta \mathrm{T}$ Cells Involve in Mucosal IgZ Production}

The abundance of $\gamma \delta \mathrm{T}$ cells in mucosal tissue is reminiscent of some connection between $\gamma \delta \mathrm{T}$ cells and mucosal immunity. To test this hypothesis, we initially observed the distribution of $\gamma \delta$ $\mathrm{T}$ cells in the posterior intestine, which have been considered to play an important role in the mucosal immune responses of fish. Immunofluorescence demonstrated that $\gamma \delta \mathrm{T}$ cells were prevalent in the gut, and the $\gamma \delta \mathrm{T}$ cells considerably accumulated in the lamina propria of the stimulated fish (Figure 9A). The antigen-specific IgZ response was subsequently examined in the $\gamma \delta \mathrm{T}$ cell-depleted group. Compared with the KLH-immunized control group, the KLH-immunized group administered with non-related IgG (negative control) produced almost identical IgZ levels. Conversely, the levels of IgZ antibody were lower in the $\gamma \delta \mathrm{T}$ cell-depleted group, the CsA addition group, and the $\alpha \beta$ T cell-depleted group (Figure 9B). The mRNA expression levels of IgZ were similarly downregulated in the hind-gut of $\gamma \delta \mathrm{T}$ cell-depleted and CsA-administered groups. The alteration of IgZ in various experimental groups was accompanied by a similar change in CD40 expression. This finding implied that CD40-mediated co-stimulatory regulation may be involved in the IgZ production (Figure 9D). In the adoptive experiment, antigen $(\mathrm{KLH})$-specific IgZ production can be restored to a normal level when KLH-pulsed $\gamma \delta$ T cells are transferred in the presence of $\alpha \beta$ $\mathrm{T}$ cells. KLH-specific IgZ production can also recover to a certain degree in the absence of $\alpha \beta \mathrm{T}$ cells in the $\alpha \beta \mathrm{T}$ cell-depleted group (Figure 9C). These results imply that $\alpha \beta$ T cell-dependent mechanism may be largely responsible for antigen-specific mucosal IgZ production; however, there might also exist an $\alpha \beta$ $\mathrm{T}$ cell-independent mechanism underlying IgZ production.

\section{DISCUSSION}

Since the discovery of $\gamma \delta$ T cells in the mid-1980s in humans, these cells have been considered as an enigmatic population that 

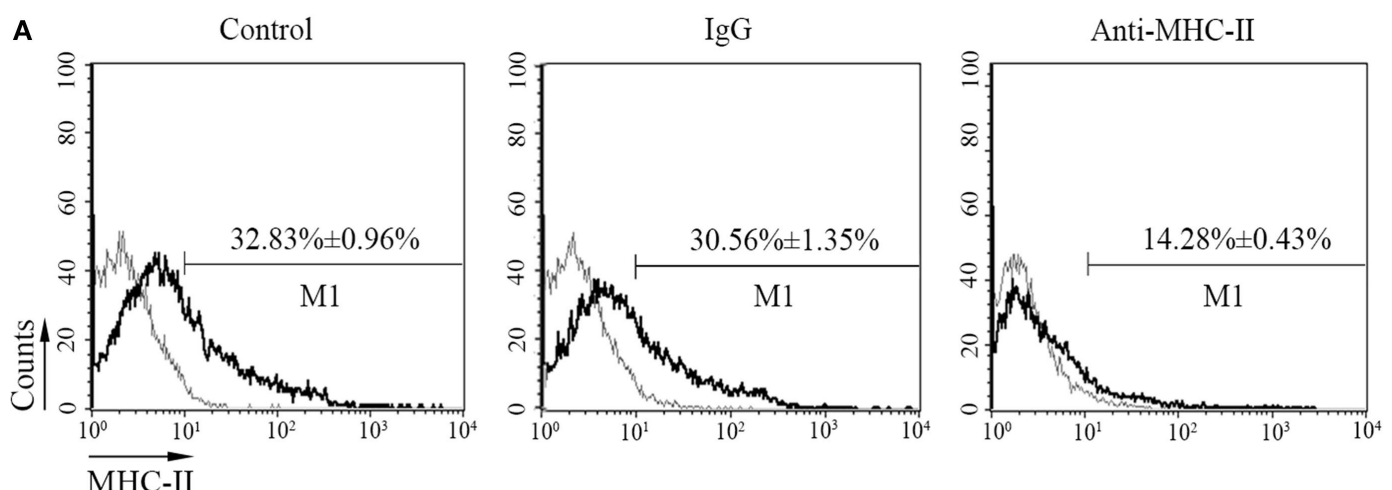

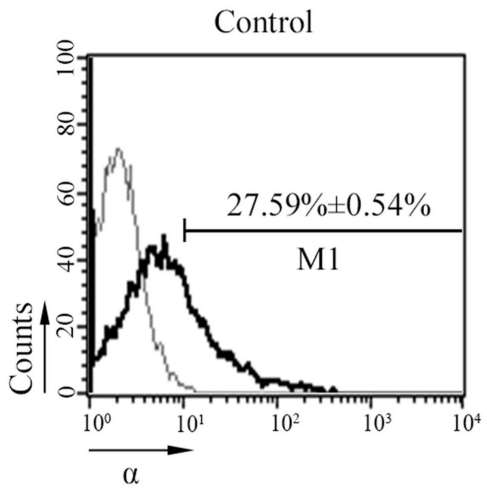

B

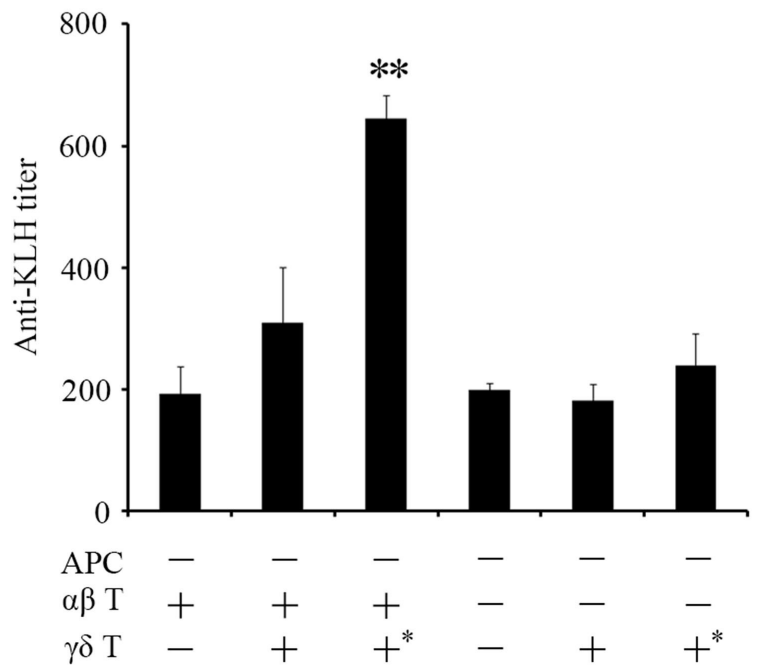

C

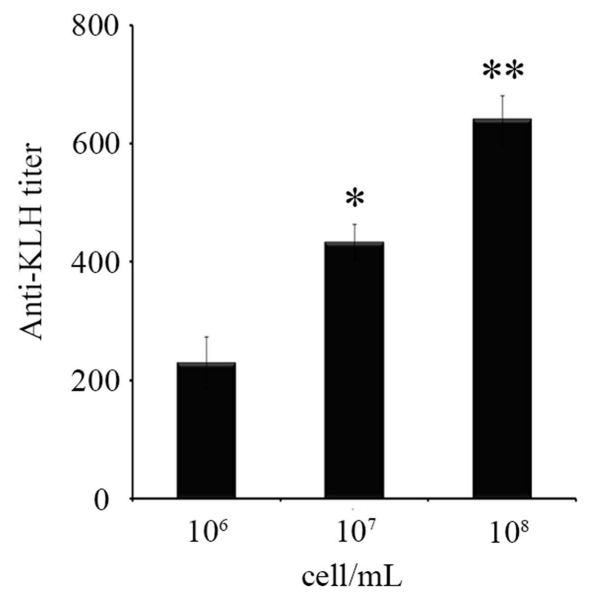

FIGURE 8 An adoptive transfer assay of $\gamma \delta$ T cells in the IgM production. (A) The effect of anti-MHC-II Ab and anti- $\alpha / \beta$ Abs on in vivo depletion of antigen-presenting cells (APCs) and $\alpha \beta$ T cells were assessed by FCM. Negative controls treated with PBS or normal rabbit lgG were created. Light gray graphs show the background staining with an irrelevant $\mathrm{Ab}$ on the target gated population. The numbers above the marker bars indicate the percentage of $\mathrm{MHC}-\mathrm{II}^{+} \mathrm{APC}$ and $\alpha^{+} T$ cells in each treatment group. Each result was obtained from 30 fishes. (B) ELISA for KLH-specific IgM Abs in the serum of fishes received adoptive transfer in different-treatment combinations. All the recipient fishes were administered with anti-MHC-II Ab to eliminate the basal MHC-II+ APCs. Double depletion of APCs and $\alpha \beta$ T cells was performed by co-administration with anti-MHC-II Ab and anti- $\alpha / \beta$ Abs into fishes followed by the transfer of $\gamma \delta$ T cells. The "APC-" group means recipient fishes with an efficient APC-depletion as shown in (A) (upper panel); the " $\alpha \beta T-$ " group means recipient fishes with an efficient $\alpha \beta$ T cell-depletion as shown in (A) (lower panel); the " $\alpha \beta T+$ " group means recipient fishes with no depletion treatment; the " $\gamma \delta$ T-" group means recipient fishes with no $\gamma \delta T$ cell adoptive transfer; the " $\gamma \delta T+$ " group means recipient fishes received adoptive transfer of non-activated $\gamma \delta T$ cells; the " $\gamma \delta T+{ }^{*}$ " group means recipient fishes received adoptive transfer of activated $\gamma \delta$ T cells with antigen (KLH in combination of LPS) stimulation. These groups were assembled in different combinations as designated in the figure body for different experimental purpose. (C) ELISA for $\mathrm{KLH}$-specific IgM Abs in the serum from the recipient fishes transferred with different dosages (10 ${ }^{6}$, $10^{7}$, and $10^{8} \mathrm{cell} / \mathrm{mL}$ ) of activated $\gamma \delta$ T cells. All of the groups were titered from 1/100 to 1/800, and the titers were ascertained based on the highest serum dilution, at which the A450 ratio (A450 of postimmunization sera/A450 of preimmunization sera) is $\geq 2.1$. The data of the background control group with PBS administration were subtracted from each experimental group. 


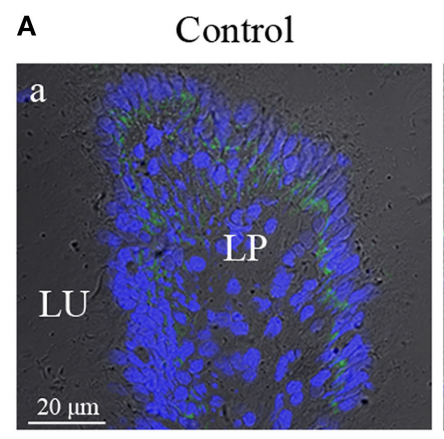

B

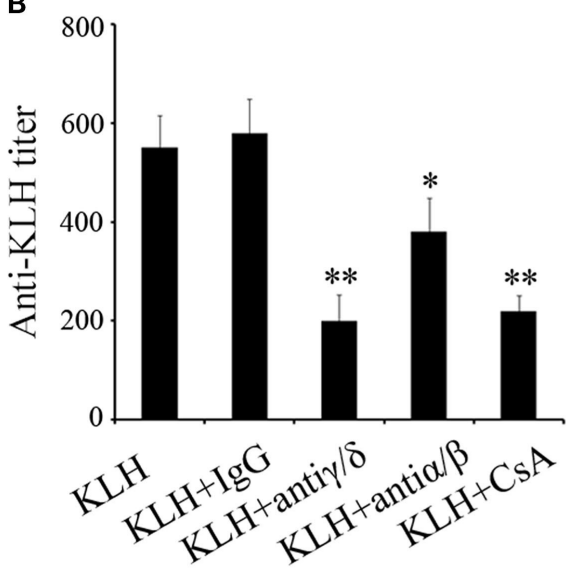

D

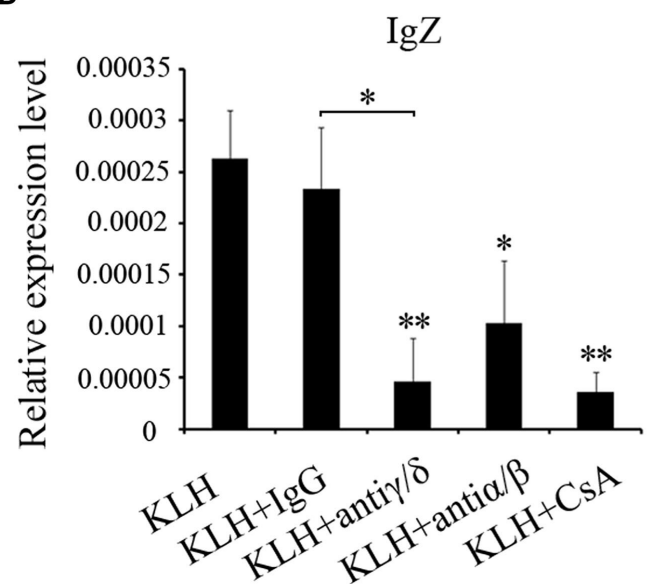

$\mathrm{KLH}$

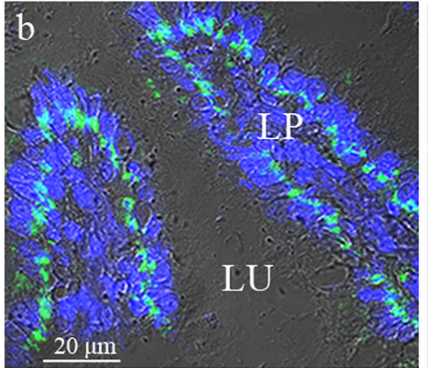

C
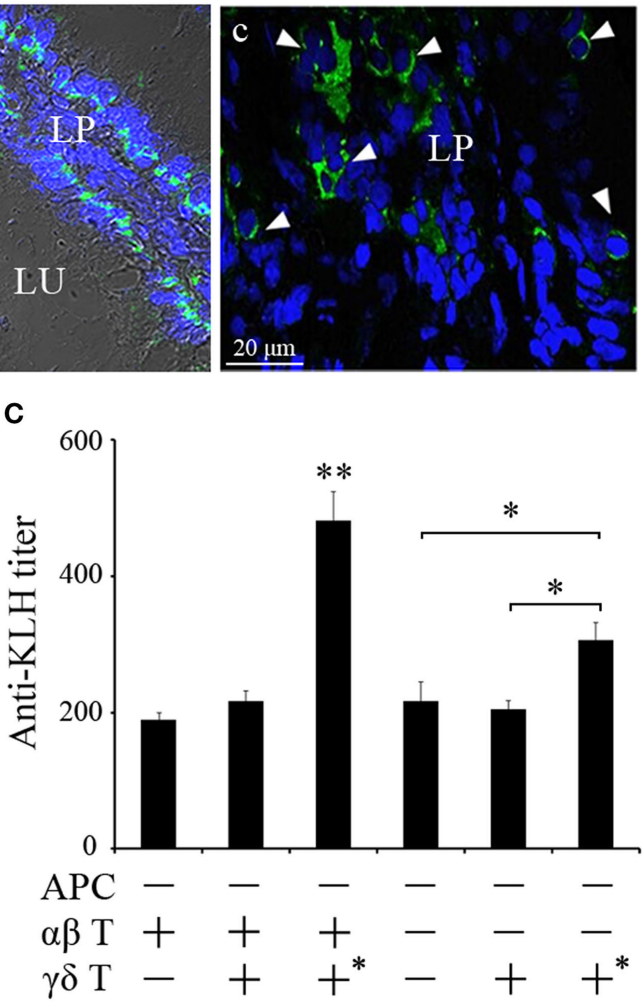

$\mathrm{KLH}$

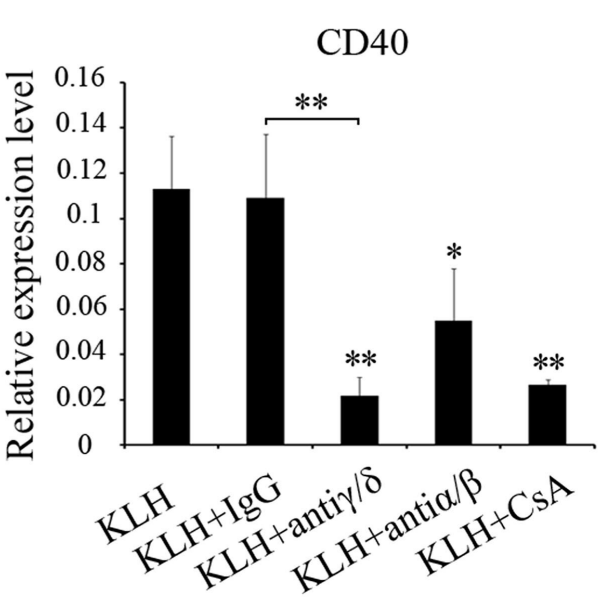

FIGURE 9 | Evaluation of zebrafish $\gamma \delta \mathbf{T}$ cells in mucosal lgZ production. (A) Differential interference contrast images of immunofluorescence staining of zebrafish hind-gut cryosections from control fish (a) and fish that had been stimulated with KLH (b), stained for DrTRGC (green) and nuclei are stained with DAPI. Enlarged images of the LP (c), without differential interference contrast, showing infiltrating $\gamma \delta$ T cells that marked with white arrows in the gut lamina propria. LP represents lamina propria and Lu represents gut lumen. (B) The titers of IgZ against KLH in each treatment group were examined by ELISA. The control groups immunized with KLH only. (C) ELISA for KLH-specific lgZ Abs in the intestine mucus from the recipient fishes with adoptive transfer in different-treatment combinations. All the treatments and combinations were consistent to that shown in Figure 8B. The titer was ascertained based on the highest serum dilution at which the A450 ratio (A450 of postimmunization sera/A450 of preimmunization sera) is $\geq 2.1$. The data of the background control group with PBS administration were subtracted from each experimental group. (D) The expression levels of lgZ and CD40 in the metenteron were determined by real-time PCR. Means \pm SD of three independent experiments are shown. ${ }^{*} P<0.05,{ }^{\star \star} P<0.01$.

exhibits the characteristics of both innate and adaptive immune functions, such as participating in rapid resistance to pathogen infections, acting as an APC to initiate adaptive immunity, and performing $\mathrm{CD} 4^{+}$Th and $\mathrm{CD} 8^{+}$CTL-like functions $(4,30)$. Thus, the $\gamma \delta \mathrm{T}$ cells are thought to be a more primordial lymphocyte subset with a long evolutionary history throughout vertebrate evolution (31). Ancient vertebrates should also be included to obtain additional insights regarding vertebrate evolution. 
Teleost fishes possess the recognizable adaptive immunity on the basis of their complicated innate immune system; as such, they are potential organisms to investigate the evolutionary history of vertebrate immune systems (32). In our study, the $\gamma \delta$ $\mathrm{T}$ cells from a zebrafish model were described through molecular and functional characterization. TCR- $\gamma$ and TCR- $\delta$ molecules were initially identified from zebrafish to show various conserved structural features of their mammalian counterparts, as determined by similar genome synteny, gene organization, and existence of the hallmarks of typical TCR sequences. Zebrafish $\gamma \delta$ T cells exhibited the surface phenotype of $\gamma^{+} \delta^{+} \mathrm{CD} 4^{-} \mathrm{CD} 8^{+}$, which is similar to that of mammalian $\gamma \delta$ T cells, by immunofluorescence staining. The magnetically sorted zebrafish $\gamma \delta$ T cells manifested lymphocyte behaviors, as shown by their distribution in the lymphoid gate in FCM analysis, and their expression of the hallmark molecules exclusive from that of $\alpha \beta$ T cells, mIgM $^{+}$B cells, and monocytes/macrophages through RT-PCR. Tissue distribution analysis demonstrated that the zebrafish $\gamma \delta$ T cells yielded the highest localization in the skin, gills, and intestine, three mucosalassociated tissues, which coincides with the supposed function of $\gamma \delta \mathrm{T}$ cells prominent in mucosal immunity. Zebrafish $\gamma \delta$ cells possess typical lymphocyte morphology, with round dense nuclei surrounded by a thin round ring of cytoplasm, a similar diameter, and numerous surface frills, as determined by TEM and SEM. Functionally, zebrafish $\gamma \delta$ T cells manifested potent non-specific phagocytic abilities for both soluble and particulate antigens and functioned as an APC to initiate the full activation of adaptive immunity, including priming antigen-specific $\mathrm{CD} 4^{+}$ $T$ cell activation, subsequent $B$ cell proliferation, and systematic IgM production. Through in vivo depletion and transfer assays, the APC function of zebrafish $\gamma \delta$ T cells was found to be in an $\alpha \beta$ $T$ cell-dependent pathway. These experimental lines suggested the presence of $\gamma \delta \mathrm{T}$ cells in zebrafish, which possess multi-faceted conservation of their mammalian $\gamma \delta$ T cells.

As one of the most important cellular components in the immune system, the origin and evolution of the T and B lymphocytes have received considerable attention; however, this topic has long been challenged in immunology because of limited information regarding $\mathrm{T}$ and $\mathrm{B}$ lymphocytes in phylogenetically ancient species $(33,34)$. B cells in mammals were thought to originate from primitive phagocytic cells, such as macrophages in ancient vertebrates. This hypothesis was recently supported by the observations that B cells in teleost fish exhibit strong phagocytic and microbicidal abilities and act as a pivotal initiating APC in priming naive $\mathrm{CD} 4^{+} \mathrm{T}$ cells and subsequent adaptive humoral immunity $(21,26)$. These characteristics are typical myeloid traits and innate-like functional features shared by macrophages. The B-1 subset and the ancient B cell lineage have been suggested to have originated from a group of ancient phagocytic ancestors similar to macrophages because B-1 cells in mammals possess similar features to those of teleost B cells $(35,36)$. Moreover, two alternative pathways have been proposed to explain the evolutionary relationship between B-1 and B-2 cell lineages (34). However, the evolutionary history of the T lymphocytes should be clarified. In our study, zebrafish $\gamma \delta \mathrm{T}$ cells also possessed potent phagocytosis and APC function on the initiation of adaptive immunity; the performance was similar to that of B cells in teleost fish. These myeloid traits and innate features shared by zebrafish $\gamma \delta$ T cells were also observed in a subtype of human V $\gamma 9 \mathrm{~V} \delta 2 \mathrm{~T}$ cells $(27,37)$, which resembling the correspondence of teleost B cells to human B-1 lineage. Thus, teleost $\gamma \delta \mathrm{T}$ cells and human V V9V82 T-like subset, as well as $\gamma \delta \mathrm{T}$ cells and B-1 lineage cells, possibly showed a close evolutionary relationship. Several phylogenetic studies favored the $\gamma \delta$ TCR having evolved before both the $\alpha \beta$ TCR and B cell Igs because of the following reasons (31): first, the evolutionary trees based on the $\mathrm{C}$ region sequences of four TCRs and two Igs suggest that TCR evolved earliest; then, they produce $\operatorname{IgL}$ and $\operatorname{IgH}$; second, the primordial immune cells should be capable of recognizing a wide array of antigens. Third, tree topologies indicated that direct antigen recognition is more primitive than that of indirect antigen recognition, as $\alpha \beta$ TCRs do. Membrane-bound forms were regarded as an ancestral characteristic, and the secretion of Igs was likely a derived trait. These findings point the finger at the origin of $\mathrm{T}$ and $\mathrm{B}$ lymphocytes, which ultimately attribute to the origin of TCR and BCR. Taken together, it seems reasonable to assume that $\mathrm{T}$ cells were probably ancestral immune cells; $\gamma \delta$ T-like cells may be a more primordial subpopulation that gave rise to $\alpha \beta$ T cells and $\mathrm{B}$ cells. In addition, $\gamma \delta \mathrm{T}$ and $\mathrm{B}$ cells might have originated from a common phagocytic progenitor. The exact origins of $\gamma \delta$ $\mathrm{T}$ cells, $\alpha \beta$ T cells, and B cells can be fully elucidated when these cells are subjected to further cellular and functional identifications in other ectothermic vertebrates.

Typical adaptive humoral immunity employed in higher vertebrates was initially established in teleost fish on the basis of the origin of $\mathrm{mIgM}^{+} \mathrm{B}$ cells, $\mathrm{CD}^{+}$Th2-like cells, and the oldest Ig of IgM (8). However, the cellular regulatory mechanisms underlying teleost adaptive humoral immunity remain limited. A dendritic cell-like and a B-1 cell-like population have been functionally identified from several fish species, and these cells could act as APCs for antigen-specific T cell activation and IgM production $(10,21,38)$. In this study, $\gamma \delta$ T cells in zebrafish could promote antigen-specific $\mathrm{CD} 4^{+} \mathrm{T}$ cell activation and IgM production; thus, a previously unknown cellular member was added to the APC family of teleost fish. IgM is a primitive antibody from teleost fish, and a similar function was characterized in a subtype $(\mathrm{V} \gamma 9 \mathrm{~V} \delta 2 \mathrm{~T})$ of human $\gamma \delta \mathrm{T}$ cells $(37,39)$. Therefore, $\gamma \delta \mathrm{T}$ cells in IgM production may be initially participate in adaptive humoral immunity, and this function was conserved from fish to mammals throughout vertebrate evolution. Along with other Ig isotypes, such as IgA, IgE, IgD, and IgG, $\gamma \delta$ T cells and their function may expand correspondingly, as evidenced by the observations that mice deficient in individual $\gamma \delta \mathrm{T}$ subsets can manifest changes in serum Abs, including major subclasses (40). $\gamma \delta \mathrm{T}$ cells also play essential roles in IgZ (also named IgT) production, a novel Ig recently identified from zebrafish, rainbow trout, and several other fish species such as common carp $(28,41,42)$. This IgZ/T molecule has been observed as the prevalent Ig in all fish mucosaassociated lymphoid tissues (MALTs) examined, including gutassociated lymphoid tissue, skin-associated lymphoid tissue, gill-associated lymphoid tissue, and nasopharynx-associated lymphoid tissue in rainbow trout, the latter of which is a newly discovered MALT in teleost carrying conserved anatomical structures and defense functions that serve as an important 
mucosal immune barrier against pathogens in the olfactory system across vertebrate species $(28,43-47)$. Thus, teleost fish is a potential model system for the exploration of precise cellular and molecular mechanisms underlying mucosal immunity because fish have unique and highly developed mucosa immune systems for the defense against numerous microorganisms in aquatic environment. Using zebrafish model, the functions of $\gamma \delta \mathrm{T}$ cells in mucosal immune responses could be greatly improved.

In mammals, $\gamma \delta \mathrm{T}$ cells have found to be a group of highly heterogeneous cells with a variety of subtypes. They are abundant in the epithelia of various tissues such as skin, small intestine, and reproductive tract. However, $\gamma \delta$ TCR usage is usually not equivalent in different epithelia. For example, the predominant receptor of dermal epithelia using $\mathrm{V} \gamma 5$ is not used in the gut epithelium, and the predominantly used $\gamma$ gene in intestinal intraepithelial lymphocytes (I-IELs) is $\mathrm{V} \gamma 7$, the functional use of which has not been conspicuous elsewhere (48). Unlike the other epithelial $\gamma \delta$ cells, the I-IELs can employ a variety V $\delta$ seg-

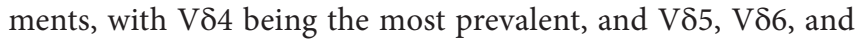
V $\delta 7$ being used less frequently (49-51). Besides, the junctions of both the $\gamma$ and $\delta$ chains exhibit considerable junctional diversity, including extensive $\mathrm{N}$-regions and the use of both $\mathrm{D}$ elements in many of the $\delta$ chains $(49,50)$. It makes I-IELs have a very large potential antigenic repertoire. So far, studies on fish $\gamma \delta$ TCR repertoire and its functional diversity are very limited. Further investigations are needed to address whether the differentiation of $\mathrm{V} \gamma \mathrm{V} \delta \mathrm{TCR}$ chains, and $\gamma \delta \mathrm{T}$ subtypes had been existed in teleost fish. Clarification on these issues would be benefit to provide valuable insights into the functional evolution of $\gamma \delta \mathrm{T}$ cell subset.

In conclusion, our studies provided the first evidence confirming that $\gamma \delta$ T cells had existed in teleost fish. These cells play an

\section{REFERENCES}

1. Brenner MB, McLean J, Dialynas DP, Strominger JL, Smith JA, Owen FL, et al. Identification of a putative second T-cell receptor. Nature (1986) 322:145-9. doi: $10.1038 / 322145 \mathrm{a} 0$

2. Saito H, Kranz DM, Takagaki Y, Hayday AC, Eisen HN, Tonegawa S. A third rearranged and expressed gene in a clone of cytotoxic T lymphocytes. Nature (1984) 312:36-40. doi:10.1038/312036a0

3. Silva-Santos B, Serre K, Norell H. $\gamma \delta$ T cells in cancer. Nat Rev Immunol (2015) 15:683-91. doi:10.1038/nri3904

4. Hayday AC. [gamma] [delta] cells: a right time and a right place for a conserved third way of protection. Annu Rev Immunol (2000) 18:975-1026. doi:10.1146/ annurev.immunol.18.1.975

5. Prinz I, Silva-Santos B, Pennington DJ. Functional development of $\gamma \delta$ T cells. Eur J Immunol (2013) 43:1988-94. doi:10.1002/eji.201343759

6. Sheridan BS, Romagnoli PA, Pham QM, Fu HH, Alonzo F III, Schubert WD, et al. gamma delta $\mathrm{T}$ cells exhibit multifunctional and protective memory in intestinal tissues. Immunity (2013) 39:184-95. doi:10.1016/ j.immuni.2013.06.015

7. Mak TW, Ferrick DA. The gamma delta T-cell bridge: linking innate and acquired immunity. Nat Med (1998) 4:764-5. doi:10.1038/Nm0798-764

8. Boehm T, Swann JB. Origin and evolution of adaptive immunity. Annu Rev Anim Biosci (2014) 2:259-83. doi:10.1146/annurev-animal-022513-114201

9. Holderness J, Hedges JF, Ramstead A, Jutila MA. Comparative biology of gamma delta T cell function in humans, mice, and domestic animals. Annu Rev Anim Biosci (2013) 1:99-124. doi:10.1146/annurev-animal-031412-103639 essential role in the initiation of adaptive immunity. Our study also provided insights into the origin of $\mathrm{T}$ cell subset in ancient vertebrates and the functional conservation of $\gamma \delta$ T cells during evolution. Given $\gamma \delta$ T cells play pivotal roles in various immunerelevant diseases, such as rheumatoid arthritis, inflammatory bowel disease, systemic lupus erythematosus, multiple sclerosis, diabetes, and autoimmune thyroid and liver disorders (52). Zebrafish is a potential model organism that can be used to investigate the biological characteristics of $\gamma \delta$ T cells, $\gamma \delta$ T-mediated diseases, and clinical therapies.

\section{AUTHOR CONTRIBUTIONS}

Conceive and designed the experiments: J-zS and FW. Performed the experiments: FW, C-bH, and KG. Analyzed the data: FW and $\mathrm{J}-\mathrm{xM}$. Contributed reagents/materials/analysis tools: $\mathrm{L}-\mathrm{xX}$ and J-zS. FW wrote the manuscript.

\section{FUNDING}

This work was supported by grants from the National Natural Science Foundation of China (31630083, 31372554, 31472298, 31572641, 31272691); Stem Cell and Translational Research, the National Key Research and Development Program of China (2016YFA0101001); Zhejiang Major Special Program of Breeding (2016C02055-4).

\section{SUPPLEMENTARY MATERIAL}

The Supplementary Material for this article can be found online at http://journal.frontiersin.org/article/10.3389/fimmu. 2016.00675/full\#supplementary-material.
10. Lugo-Villarino G, Balla KM, Stachura DL, Bañuelos K, Werneck MB, Traver D. Identification of dendritic antigen-presenting cells in the zebrafish. Proc Natl Acad Sci U S A (2010) 107:15850-5. doi:10.1073/pnas.1000494107

11. Xu XG, Hu JF, Ma JX, Nie L, Shao T, Xiang LX, et al. Essential roles of TIM-1 and TIM-4 homologs in adaptive humoral immunity in a zebrafish model. J Immunol (2016) 196:1686-99. doi:10.4049/jimmunol.1501736

12. Monson CA, Sadler KC. Inbreeding depression and outbreeding depression are evident in wild-type zebrafish lines. Zebrafish (2010) 7:189-97. doi:10.1089/ zeb.2009.0648

13. Haire RN, Rast JP, Litman RT, Litman GW. Characterization of three isotypes of immunoglobulin light chains and T-cell antigen receptor alpha in zebrafish. Immunogenetics (2000) 51:915-23. doi:10.1007/s002510000229

14. Meeker ND, Smith AC, Frazer JK, Bradley DF, Rudner LA, Love C, et al. Characterization of the zebrafish $\mathrm{T}$ cell receptor beta locus. Immunogenetics (2010) 62:23-9. doi:10.1007/s00251-009-0407-6

15. Yazawa R, Cooper GA, Beetz-Sargent M, Robb A, McKinnel L, Davidson WS, et al. Functional adaptive diversity of the Atlantic salmon T-cell receptor gamma locus. Mol Immunol (2008) 45:2150-7. doi:10.1016/j.molimm.2007.12.007

16. Schorpp M, Bialecki M, Diekhoff D, Walderich B, Odenthal J, Maischein HM, et al. Conserved functions of Ikaros in vertebrate lymphocyte development: genetic evidence for distinct larval and adult phases of $\mathrm{T}$ cell development and two lineages of B cells in zebrafish. J Immunol (2006) 177:2463-76. doi:10.4049/jimmunol.177.4.2463

17. Hopp TP, Woods KR. Prediction of protein antigenic determinants from amino acid sequences. Proc Natl Acad Sci US A (1981) 78:3824-8. doi:10.1073/ pnas.78.6.3824 
18. Peters B, Sidney J, Bourne P, Bui HH, Buus S, Doh G, et al. The immune epitope database and analysis resource: from vision to blueprint. PLoS Biol (2005) 3:e91. doi:10.1371/journal.pbio.0030091

19. Zhu LY, Pan PP, Fang W, Shao JZ, Xiang LX. Essential role of IL-4 and IL-4R alpha interaction in adaptive immunity of zebrafish: insight into the origin of Th2-like regulatory mechanism in ancient vertebrates. J Immunol (2012) 188:5571-84. doi:10.4049/jimmunol.1102259

20. Bordeaux J, Welsh A, Agarwal S, Killiam E, Baquero M, Hanna J, et al. Antibody validation. Biotechniques (2010) 48:197-209. doi:10.2144/000113382

21. Zhu LY, Lin AF, Shao T, Nie L, Dong WR, Xiang LX, et al. B cells in teleost fish act as pivotal initiating APCs in priming adaptive immunity: an evolutionary perspective on the origin of the B-1 cell subset and B7 molecules. J Immunol (2014) 192:2699-714. doi:10.4049/jimmunol.1301312

22. Gong YF, Xiang LX, Shao JZ. CD154-CD40 interactions are essential for thymus-dependent antibody production in zebrafish: insights into the origin of costimulatory pathway in helper $\mathrm{T}$ cell-regulated adaptive immunity in early vertebrates. J Immunol (2009) 182:7749-62. doi:10.4049/ jimmunol.0804370

23. Lin AF, Xiang LX, Wang QL, Dong WR, Gong YF, Shao JZ. The DC-SIGN of zebrafish: insights into the existence of a CD209 homologue in a lower vertebrate and its involvement in adaptive immunity. JImmunol (2009) 183:7398-410. doi:10.4049/jimmunol.0803955

24. Hu YL, Xiang LX, Shao JZ. Identification and characterization of a novel immunoglobulin $\mathrm{Z}$ isotype in zebrafish: implications for a distinct $\mathrm{B}$ cell receptor in lower vertebrates. Mol Immunol (2010) 47:738-46. doi:10.1016/ j.molimm.2009.10.010

25. Traver D, Paw BH, Poss KD, Penberthy WT, Lin S, Zon LI. Transplantation and in vivo imaging of multilineage engraftment in zebrafish bloodless mutants. Nat Immunol (2003) 4:1238-46. doi:10.1038/ni1007

26. Li J, Barreda DR, Zhang YA, Boshra H, Gelman AE, Lapatra S, et al. B lymphocytes from early vertebrates have potent phagocytic and microbicidal abilities. Nat Immunol (2006) 7:1116-24. doi:10.1038/ni1389

27. Wu Y, Wu W, Wong WM, Ward E, Thrasher AJ, Goldblatt D, et al. Human gamma delta T cells: a lymphoid lineage cell capable of professional phagocytosis. J Immunol (2009) 183:5622-9. doi:10.4049/jimmunol.0901772

28. Zhang YA, Salinas I, Li J, Parra D, Bjork S, Xu Z, et al. IgT, a primitive immunoglobulin class specialized in mucosal immunity. Nat Immunol (2010) 11:827-35. doi:10.1038/ni.1913

29. Trede NS, Langenau DM, Traver D, Look AT, Zon LI. The use of zebrafish to understand immunity. Immunity (2004) 20:367-79. doi:10.1016/ S1074-7613(04)00084-6

30. Ribeiro ST, Ribot JC, Silva-Santos B. Five layers of receptor signaling in gamma delta T-cell differentiation and activation. Front Immunol (2015) 6:15. doi:10.3389/Fimmu.2015.00015

31. Richards MH, Nelson JL. The evolution of vertebrate antigen receptors: a phylogenetic approach. Mol Biol Evol (2000) 17:146-55. doi:10.1093/oxfordjournals.molbev.a026227

32. Lieschke GJ, Trede NS. Fish immunology. Curr Biol (2009) 19:R678-82. doi:10.1016/j.cub.2009.06.068

33. Kawamoto H. A close developmental relationship between the lymphoid and myeloid lineages. Trends Immunol (2006) 27:169-75. doi:10.1016/ j.it.2006.02.004

34. Zhu LY, Shao T, Nie L, Zhu LY, Xiang LX, Shao JZ. Evolutionary implication of B-1 lineage cells from innate to adaptive immunity. Mol Immunol (2016) 69:123-30. doi:10.1016/j.molimm.2015.10.014

35. Gao J, Ma X, Gu W, Fu M, An J, Xing Y, et al. Novel functions of murine B1 cells: active phagocytic and microbicidal abilities. Eur J Immunol (2012) 42:982-92. doi:10.1002/eji.201141519

36. Parra D, Rieger AM, Li J, Zhang YA, Randall LM, Hunter CA, et al. Pivotal advance: peritoneal cavity B-1 B cells have phagocytic and microbicidal capacities and present phagocytosed antigen to CD4(+) T cells. J Leukoc Biol (2012) 91:525-36. doi:10.1189/jlb.0711372
37. Brandes M, Willimann K, Moser B. Professional antigen-presentation function by human gammadelta T cells. Science (2005) 309:264-8. doi:10.1126/ science. 1110267

38. Bassity E, Clark TG. Functional identification of dendritic cells in the teleost model, rainbow trout (Oncorhynchus mykiss). PLoS One (2012) 7(3):e33196. doi:10.1371/journal.pone.0033196

39. Fillatreau S, Six A, Magadan S, Castro R, Sunyer JO, Boudinot P. The astonishing diversity of Ig classes and B cell repertoires in teleost fish. Front Immunol (2013) 4:28. doi:10.3389/fimmu.2013.00028

40. Huang Y, Heiser RA, Detanico TO, Getahun A, Kirchenbaum GA, Casper TL, et al. gamma delta T cells affect IL-4 production and B-cell tolerance. Proc Natl Acad Sci U S A (2015) 112:E39-48. doi:10.1073/pnas. 1415107111

41. Danilova N, Bussmann J, Jekosch K, Steiner LA. The immunoglobulin heavy-chain locus in zebrafish: identification and expression of a previously unknown isotype, immunoglobulin Z. Nat Immunol (2005) 6:295-302. doi:10.1038/ni1166

42. Ryo S, Wijdeven RH, Tyagi A, Hermsen T, Kono T, Karunasagar I, et al. Common carp have two subclasses of bonyfish specific antibody IgZ showing differential expression in response to infection. Dev Comp Immunol (2010) 34:1183-90. doi:10.1016/j.dci.2010.06.012

43. Xu Z, Parra D, Gómez D, Salinas I, Zhang YA, von Gersdorff Jørgensen L, et al. Teleost skin, an ancient mucosal surface that elicits gut-like immune responses. Proc Natl Acad Sci U S A (2013) 110:13097-102. doi:10.1073/ pnas. 1304319110

44. Xu Z, Takizawa F, Parra D, Gómez D, von Gersdorff Jørgensen L, LaPatra SE, et al. Mucosal immunoglobulins at respiratory surfaces mark an ancient association that predates the emergence of tetrapods. Nat Commun (2016) 7:10728. doi:10.1038/Ncomms10728

45. Tacchi L, Musharrafieh R, Larragoite ET, Crossey K, Erhardt EB, Martin SA, et al. Nasal immunity is an ancient arm of the mucosal immune system of vertebrates. Nat Commun (2014) 5:5205. doi:10.1038/Ncomms6205

46. Salinas I. The mucosal immune system of teleost fish. Biology (Basel) (2015) 4:525-39. doi:10.3390/biology4030525

47. Sepahi A, Salinas I. The evolution of nasal immune systems in vertebrates. Mol Immunol (2016) 69:131-8. doi:10.1016/j.molimm.2015 09.008

48. Kyes S, Carew E, Carding SR, Janeway CA, Hayday A. Diversity in T-cell receptor gamma-gene usage in intestinal epithelium. Proc Natl Acad Sci U S A (1989) 86:5527-31. doi:10.1073/pnas.86.14.5527

49. Asarnow DM, Goodman T, Lefrancois L, Allison JP. Distinct antigen receptor repertoires of two classes of murine epithelium-associated T cells. Nature (1989) 341:60-2. doi:10.1038/341060a0

50. Takagaki Y, Decloux A, Bonneville M, Tonegawa S. Diversity of $\gamma \delta$ T-cell receptors on murine intestinal intraepithelial lymphocytes. Nature (1989) 339:712-4. doi:10.1038/339712a0

51. Allison JP, Havran WL. The immunobiology of $\mathrm{T}$ cells with invariant gammadelta antigen receptors. Immunology (1991) 9:1077-90. doi:10.1146/ annurev.iy.09.040191.003335

52. Paul S, Shilpi, Lal G. Role of gamma-delta $(\gamma \delta)$ T cells in autoimmunity. J Leukoc Biol (2015) 97:259-71. doi:10.1189/jlb.3RU0914-443R

Conflict of Interest Statement: The authors declare that the research was conducted in the absence of any commercial or financial relationships that could be construed as a potential conflict of interest.

Copyright $\odot 2017$ Wan, Hu, Ma, Gao, Xiang and Shao. This is an open-access article distributed under the terms of the Creative Commons Attribution License (CC BY). The use, distribution or reproduction in other forums is permitted, provided the original author(s) or licensor are credited and that the original publication in this journal is cited, in accordance with accepted academic practice. No use, distribution or reproduction is permitted which does not comply with these terms. 